\title{
Lake Volume Monitoring from Space
}

\author{
J.-F. Crétaux ${ }^{1} \cdot$ R. Abarca-del-Río ${ }^{2} \cdot$ M. Bergé-Nguyen ${ }^{1}$ • \\ A. $\operatorname{Arsen}^{3}$ - V. Drolon ${ }^{3}$ G. $\operatorname{Clos}^{1}$ - P. Maisongrande ${ }^{1}$
}

Received: 11 September 2015/ Accepted: 20 January 2016/Published online: 8 February 2016

(C) The Author(s) 2016. This article is published with open access at Springerlink.com

\begin{abstract}
Lakes are integrators of environmental change occurring at both the regional and global scale. They present a wide range of behavior on a variety of timescales (cyclic and secular) depending on their morphology and climate conditions. Lakes play a crucial role in retaining and stocking water, and because of the significant global environmental changes occurring at several anthropocentric levels, the necessity to monitor all morphodynamic characteristics [e.g., water level, surface (water contour) and volume] has increased substantially. Satellite altimetry and imagery are now widely used together to calculate lake and reservoir water storage changes worldwide. However, strategies and algorithms to calculate these characteristics are not straightforward, and specific approaches need to be developed. We present a review of some of these methodologies by using lakes over the Tibetan Plateau to illustrate some critical aspects and issues (technical and scientific) linked to the observation of climate change impact on surface waters from remote sensing data. Many authors have measured water variation using the limited remote sensing measurements available over short time periods, even though the time series are probably too short to directly link these results with climate change. Indeed, there are many processes and factors, like the influence of lake morphology, that are beyond observation and are still uncertain. The time response for lakes to reach a new state of equilibrium is a key aspect that is often neglected in current literature. Observations over a long period of time, including maintaining a constellation of comprehensive and complementary satellite missions with service continuity over decades, are therefore necessary especially when the ground gauge network is too limited. In addition, the design of future satellite missions with new instrumental concepts (e.g., SAR, SARin, Ka band altimetry, Ka interferometry) will also be suitable for complete monitoring of continental waters.
\end{abstract}

J.-F. Crétaux

jean-francois.cretaux@legos.obs-mip.fr

1 Legos/CNES, 14 Avenue Edouard Belin, 31400 Toulouse, France

2 Departamento de Geofísica (DGEO), Universidad de Concepción (UDEC), 160-C, Concepción, Chile

3 Legos/CNRS, 14 Avenue Edouard Belin, 31400 Toulouse, France 
Keywords Satellite altimetry and imagery $\cdot$ Lakes $\cdot$ Climate change $\cdot$ Tibetan Plateau

\section{Introduction}

Water is an unavoidable need for all life on Earth. An adequate supply of clean, safe, freshwater is a basic prerequisite for human survival and the economic development of regions and nations. However, water is unevenly distributed in space or in time and does not always coincide with our consumption needs and wants (domestic, agricultural or industrial). On a global scale, water runoff is largely concentrated in the temperate climatic zones and equatorial regions. The general geographical distribution of the world's lakes is also very irregular with most of them being located over the Northern Hemisphere and at higher latitudes in glaciated areas (Downing et al. 2006). Lakes and reservoirs constitute essential elements of the hydrological and biogeochemical water cycles due to their basic ability to store, retain, clean, and provide water consistently. They influence many facets of ecology, biodiversity (Dudgeon et al. 2006), the economy, and human welfare (Rast and Straskraba 2000). It therefore follows that lakes are important modifiers of many biochemical and hydrological processes. Lakes vary physically in terms of illumination levels (incoming radiation), temperature, and water currents and also have chemical variations in terms of nutrients, major ions, and contaminants. Biological variations can be noted in terms of structure and function as well as static versus dynamic variables, such as biomass, population numbers, and growth rates. All these variables present spatial and temporal variability, the latter going from minutes to geological times (see Rast and Straskraba 2000). Lake, reservoir, and wetland distribution is of great interest in many scientific disciplines. Besides their regional significance, global distribution is of special interest for large-scale studies of environment, biodiversity, health (spread of waterborne diseases), agricultural suitability, climate change modeling, and for assessments of present and future water resources (Williamson et al. 2009). Despite their importance, many considered continental waters to be a minor part of the biosphere, and therefore, until very recently, the activity of inland waters was ignored in global estimates of ecosystem processes (see Downing 2010). Now it is recognized that freshwater ecosystems play a substantial role in many key processes, such as within anthropogenic gases flux exchanges (Tranvik et al. 2009; Raymond et al. 2013; Seekel et al. 2014). It was only until very recently that there were still major uncertainties in these global estimates because many key processes (physical, chemical, and biological) scale with lake size and the total area and distribution of lentic ecosystems were not well reported.

There are a limited number of comprehensive worldwide lake datasets (Halbfass 1914; Meybeck 1995; Lehner and Döll 2004; Downing et al. 2006; McDonald et al. 2012) that contain information on location, extent, and other basic characteristics of open water bodies and wetland areas on a global scale. The recent developments in the field of remote sensing have improved these datasets and promise global land cover images of increasing quality and resolution, including the possibility to monitor spatiotemporal changes in lake and wetland extents. Verpoorter et al. (2014) made a recent inventory of global lakes using satellite imagery with production of contours for all lakes that are greater than $0.002 \mathrm{~km}^{2}$, which is currently the most complete existing database. They counted more than 117 million lakes for a total surface area of $5,000,000 \mathrm{~km}^{2}$. 
Since the middle of the 1990's, satellite radar altimetry has been a successful technique for monitoring height variations of continental surface water, such as lakes and rivers (Morris and Gill 1994; Alsdorf et al. 2001; Calmant et al. 2008; Abarca-del-Rio et al. 2012; Sima et al. 2013; Yi et al. 2013; Silva et al. 2014; Pandey et al. 2014; Tarpanelli et al. 2015 and many others). The surface water level is measured within a terrestrial reference frame with repeatability varying from 10 to 35 days depending on the orbit cycle of the satellite. Although data acquisition is independent from weather conditions, radar altimetry can have a few limitations; i.e., lake-shore topography may affect elevation calculations from the altimeter. In some extreme cases of mountain lakes, echoes can be foreseen and tracked several kilometers before and after the satellite passes causing slant range estimation (Arsen et al. 2015). Many measurements can be lost due to the presence of other small water bodies at different altitudes in the vicinity of the main target. Accuracy of elevation retrieval is also dependent on lake or river size and also on surface roughness. Finally, an altimeter is a nadir pointing system and therefore does not have a global view of the planet. However, the altimetry technique permits systematic continental-scale lake and river monitoring and can provide water level estimations in remote areas where in situ data are not available. Another advantage of satellite altimetry is its ability to monitor lakes and rivers over decades with a revisit on each target ranging from a few days to a few months depending on the orbit. For example, the TOPEX/Poseidon or Jason-1 and Jason-2 satellites have a cycle of 10 days, while for CryoSat-2 the revisit cycle is 369 days allowing a very dense coverage of the Earth's surface. For large lakes, many satellites can pass over them providing continuous surveillance over decades.

A lake acts as an integrator of climate change (Adrian et al. 2009; Schindler 2009), from seasonal to inter-annual and secular scales, with different response times depending on its morphology (Mason et al. 1994). The water stored in lakes responds (directly and indirectly) to any changes in precipitation and air temperature (Robertson and Ragotzkie 1990; De Wit and Stankiewicz 2006).

Climate change impacts lakes in many different ways. For example, increasing air temperature in mountain areas accelerates glacial thawing leading to a dramatic increase in surface runoff like over the Tibetan Plateau (Wang et al. 2012; Gao et al. 2015) or the Andean chain (Bliss et al. 2014; López-Moreno et al. 2014). Meanwhile, the increasing air temperature also enhances evapotranspiration over the lake's watershed, therefore leading to diminished runoff. It is clear that mountain lakes are also directly influenced by changes in precipitation (Kang et al. 2010; Lei et al. 2014). In tropical regions, the exchange of water between ocean and atmosphere has a direct impact on continental waters at seasonal and inter-annual timescales. The lakes in eastern Africa are a case in point. Many authors have investigated these links, especially between large lakes like Victoria, Malawi or Tanganyika, and the Indian Ocean. They have shown that the role of the Indian Ocean in the water level time series is significantly correlated with El-Niño (Nicholson and Yi 2002) or with the Indian Ocean Dipole (Tierney et al. 2013). In arid regions the impact of climate change may also be very significant, although it can be masked by human use of water resources. This is the case in Central Asia for example, where the Aral Sea started to shrink in the 1960's due to irrigation of the central Asian steppes for agricultural development, but this shrinkage has also been enhanced by climate warming (Aus Der Beck et al. 2011; Cretaux et al. 2013b). Lakes also play a major role in the water cycle processes of the boreal regions. These regions (like Siberia or Canada) are characterized by the presence of large flooded areas and a very dense network of hundreds of lakes. This includes a mix of both permanent and temporary lakes. The result is a high rate of evaporation in summertime, while in winter most of these lakes are covered with ice (Kouraev et al. 2007). 
For example, inter-annual changes of lake areas in the Yukon Valley (Alaska) were quantified over the period 1954-2000 by Altmann et al. (2010) who found that 2300 lakes increased, 430 shrank, and only 200 remained unchanged. Moreover, the role of lakes and reservoirs in the prediction of future climate impact on water resources is now taken into account in hydrological and atmospheric models (Bowling and Lettenmaier 2010; Balsamo et al. 2012).

It is therefore essential to measure their elevation changes over very long time periods, which will reinforce interest in multi-satellite constellations. As a final point on large lakes, depending on size and wind conditions accuracy is relatively good compared with in situ measurements as it may reach down to a few centimeters (e.g., the Great Lakes of North America, large lakes in East Africa or in Central Asia, Cretaux et al. 2011; Cheng et al. 2010; Ričko et al. 2012). For smaller lakes, accuracy of satellite altimetry is reduced but generally kept lower than the amplitude of inter-annual variability of the lake level (it may reach several meters or decameters for some artificial reservoirs), which in the absence of other measurements (e.g., in situ) remains a useful source of information for different purposes ranging from science to operational (Cretaux et al. 2015). It is impossible to measure lake and reservoir level variations globally from ground measurements. Furthermore, satellite radar altimetry techniques have moved from being experimental to fully operational under space agencies' program frameworks from many parts of the world (Europe, USA, China, and India) allowing continuity of service.

Lake surveying is an important objective for WMO (World Meteorological Organization) and GCOS (Global Climate Observing System) as lakes are potential proxies within the framework of global climate variability. In actual fact, the volume of water in a surface storage unit at any time is an integrator variable, reflecting both atmospheric (precipitation, evaporation energy) and hydrological (surface water recharge, discharge and ground water tables) conditions. Thus, within the few Essential Climate Variables (ECVs) (see http:// www.gosic.org/ios/MATRICES/ECV/ECV-matrix.htm and http://www.fao.org/gtos/doc/ pub52.pdf) defined to support the work of the United Nations Framework Convention on Climate Change (UNFCCC) and the Intergovernmental Panel on Climate Change (IPCC), one of these variables refers to water level changes and 79 lakes worldwide have been selected by the Global Terrestrial Network for Lakes (GTN-L) for monitoring (see http:// www.gosic.org/content/gcos-terrestrial-ecv-lakes and http://www.gosic.org/sites/default/ files/ECVT4-Lakes.pdf). For that reason, a data collection center (called Hydrolare, see http://hydrolare.net/database.php) has been created under the sponsorship of GCOS and GTOS (Global Terrestrial Observing System) and is hosted by the State Hydrological Institute of St Petersburg in Russia. Its function is to maintain a Web database for delivery of the ECVs of the lakes in the GTN-L list (see http://www.wmo.int/pages/prog/gcos/ documents/GTN-L_List.pdf) based on synergy of in situ gauges (working with national hydrological services and other institutions and agencies providing and holding data on lakes and reservoirs) and remote sensing data, principally satellite altimeter measurements.

The Hydroweb database (http://www.legos.obs-mip.fr/en/soa/hydrologie/hydroweb/) was created by Legos (Toulouse, France) in 2003, and delivers the water level of 230 lakes and volume of about 100 lakes and is officially associated with Hydrolare. Hydroweb products are completely based on satellite altimetry and imagery.

In Sect. 2 of this paper, we provide a general introduction to satellite altimetry. In Sect. 3 we concentrate on satellite imagery, and in Sect. 4 we demonstrate how to calculate lake water storage changes by a combination of both these techniques, and the Hydroweb database is briefly presented. In Sect. 5 we illustrate how to apply these techniques to a regional case study of lakes covering the Tibetan Plateau (TP). 


\section{Satellite Altimetry}

\subsection{Introduction}

The first satellite altimeter to be launched was GEOS-III in 1975, followed in 1978 by Seasat. The first use of satellite altimetry for hydrology was with GEOSAT launched in 1985 (Koblinsky et al. 1993). However, thanks to substantial progress in orbit determination from geodetic systems such as Doris, the use of GPS and laser started with the launch of the US/French TOPEX/Poseidon (T/P) satellite in 1992. Two pioneering papers published by same author in the 1990's using satellite altimetry are still considered 20 years later as basic references for lakes (Birkett 1995) and for rivers (Birkett 1998).

Since then, many studies have illustrated certain case studies using satellite altimetry for lake surveys (Birkett et al. 1999; Aladin et al. 2005; Coe and Birkett 2005; Hwang et al. 2005; Medina et al. 2008; Lee et al. 2011; Singh et al. 2012; Kleinherenbrink et al. 2015 and many others). The information obtained by this technique is the average water level above a reference surface for a set of lakes once they are overpassed by the satellite. Indeed, current satellite altimeter missions were all based on the measurements made by the altimeter at the nadir of the satellite. Therefore, only a constellation of several satellites may allow monitoring a large number of lakes and reservoirs. For example, Cretaux et al. (2015) have shown that, over the Syr Darya river in Central Asia, all the small reservoirs located within its watershed will be monitored with a constellation of Sentinel-3A (hereinafter S3A), Sentinel-3B (hereinafter S3B), Jason-3, Jason-CS/Sentinel-6, and SARAL/ AltiKa.

\subsection{Basics of Satellite Altimetry}

Satellite altimeters are designed to measure the two-way travel time of short radar (or laser) pulses reflected from the Earth's surface which gives the distance between the satellite and the reflected surface, called "range." The shape of the reflected signal, known as the "waveform," represents the power distribution of accumulated echoes as the radar pulse hits the surface. The waveforms that are acquired using a tracking system placed onboard the satellite are called "trackers" and can be modeled by a theoretical shape from which the time for the signal to be bounced back can be determined. The travel time is calculated using a predefined analytic function, which fits the time distribution of the reflected energy. The first altimetry missions were designed for the ocean domain. Therefore, the algorithm elaborated to process the waveform were fitted to classic ocean surfaces described in Brown (1977) where it is considered that thermal noise is followed by a rapid rise of the returned power called 'leading edge', and a gentle end sloping plateau known as 'trailing edge.' However, over the continents the waveforms are generally contaminated by noise resulting from multiple land returns such as vegetation, bare sands, or steep shorelines. Consequently, the shape of the echoes reflected by continental waters is often very different from that reflected by the ocean surface. It can thus become difficult, if not impossible, to calculate a river or small lake's water level using the classic "Brown" analytic function.

One way of working around this is to use alternative and more suitable retracking functions of the waveforms. With the Envisat mission launched by ESA in 2002, it was decided to provide the users the measurement ranges using four different retracking algorithms: The OCOG/ICE-1 (Wingham et al. 1986) and ICE-2 (Legresy and Remy 1997) retrackers have been developed to recover heights over ice sheets, and the SEA-ICE (Laxon 1994) to recover 
heights over sea ice. In general, for large lakes the ocean tracker is well suited, but for rivers and small lakes the OCOG/ICE1 retracking algorithm is the preferred one as it has proven to be more accurate over this type of surface than the other three (Frappart et al. 2006). Other retracking algorithms designed for hydrological waveform analysis have been developed. Berry et al. (2005) proposed to classify the waveform by their typology and to apply a different algorithm for each class. This has been applied within the automatic near-real-time altimetry data processing to all flying altimetry missions and delivered through the "River\&lake" Website (http://www.tethys.eaprs.cse.dmu.ac.uk/RiverLake), as well as to the historical missions. Another algorithm was developed for automatic calculation of lake and river time series of the DAHITI database (http://www.dahiti.dgfi.tum.de: Schwatke et al. 2015). All retracking algorithms are potentially affected by biases because they do not measure the same physical quantity (some track the very nadir point, others process spatial average within the footprint). Taking into account these biases is essential when combining ranges from different trackers of a mission, or when comparisons between different products are made (Cretaux et al. 2011a).

The water height calculation $(H)$ of a lake or river using satellite altimetry is based on the following equation:

$$
H=A l t-R-T_{E}
$$

where $H$ is considered with respect to a geoid, Alt is the altitude of the satellite above an ellipsoid, $R$ is the measured range, and $T_{E}$ is the sum of different corrections that take into account atmospheric refraction (propagation in the ionosphere and the troposphere), tidal effects (solid Earth and polar), and geoid height above the ellipsoid. For readers who need more detailed information, a full discussion of the computation of lake height and associated errors can be found in Birkett and Beckley (2010) and Cretaux et al. (2013a). Nevertheless, it is necessary here to provide some information on the specific issue of orthometric height correction due to geoid gradient along the tracks of the satellites. For propagation and tidal correction, altitude of the satellite and range measurements, these variables are provided by space agencies to the users through the Geophysical Data Records (GDRs). They also provide geoid correction; however, current products delivered in the GDRs are not accurate enough at short wavelengths for lakes. In Birkett (1995) and Crétaux and Birkett (2006) it has been shown that a specific computation must be performed to correctly account for the slope of the geoid over a distance of several hundred meters, which is far lower than the current geoid model resolution. The "repeat track technique" is used to solve this problem. The geoid slope is recalculated for each of the tracks of the satellite and then is averaged using all cycles. The result of this calculation is a mean vertical profile along the track which serves as correction for geoid in Eq. 1. Below are two examples: a mean lake profile along an ICESat track over Lake Issykkul (Fig. 1) and four individual passes over a track on Lake Ziling (Fig. 2).

\subsection{Past, Present, and Future Satellite Altimetry}

The past satellite altimeters of the class of T/P, Envisat, and Jason-2 were operating in lowresolution mode (LRM) in $\mathrm{Ku}$ Band $(13.6 \mathrm{GHz})$. Despite it not being optimal for hydrology, many studies have been based on this technique, and it has progressively led spatial agencies to include hydrological objectives in the definition of new missions. The SARAL/AltiKa mission from CNES and ISRO (French and Indian space agencies) were the first to operate in $\mathrm{Ka}$ band $(35.75 \mathrm{GHz})$ allowing a reduction in the footprint size by a 


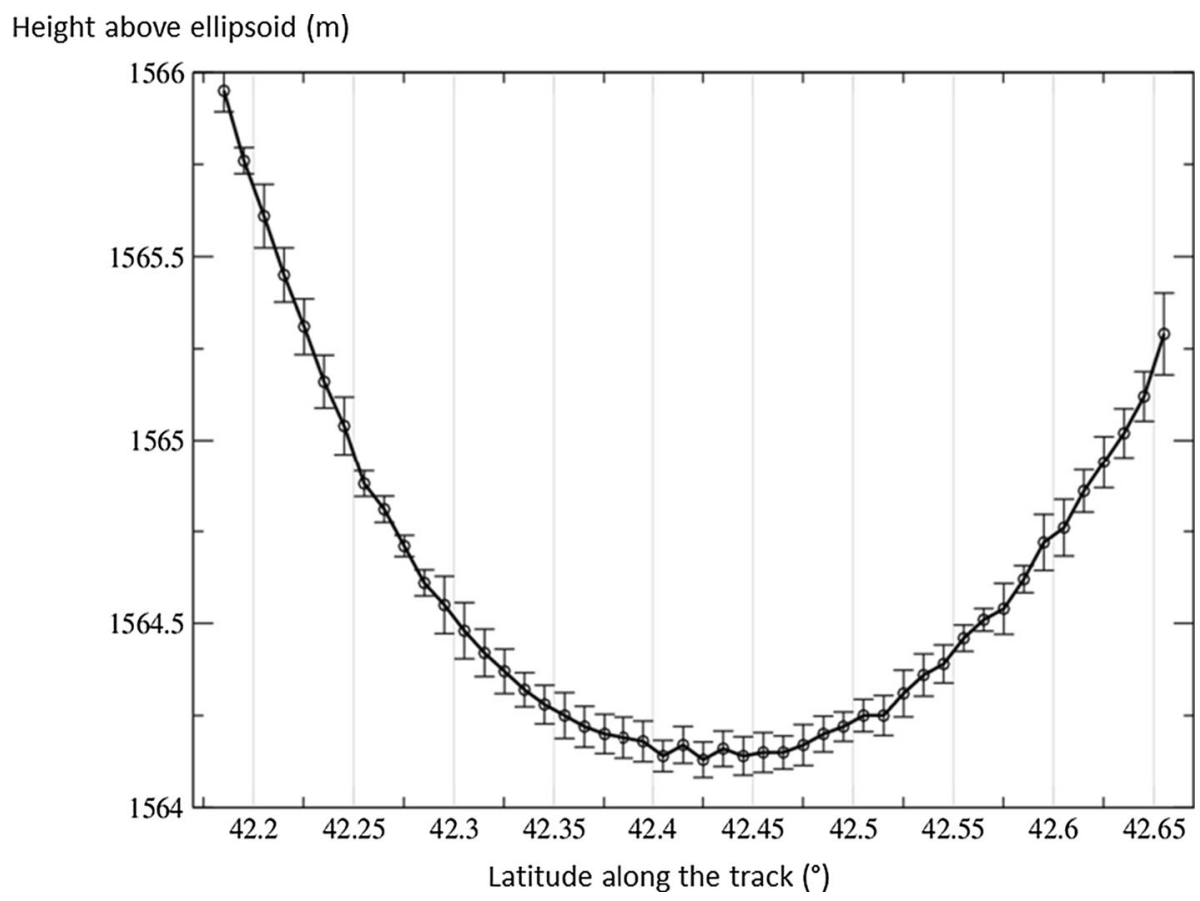

Fig. 1 Vertical mean lake profile along an ICESat track over Lake Issykkul in Central Asia

factor 2-3 and of the ionospheric effect. The hydrological interest is that the water height of many narrow rivers or reservoirs has been measured with decimeter accuracy which was not possible with past altimeters (Arsen et al. 2015). On January 17, 2016, the Jason-3 mission (same instrumental and orbital characteristics as Jason-1 and Jason-2 satellites) was launched.

On January 12, 2003, the first and only laser altimetry instrument GLAS was launched by NASA (Zwally et al. 2003). It emitted at a wavelength of 1064 and $532 \mathrm{~nm}$ on the orbiting ICESat and had a near polar, near circular orbit of 91-day repeat cycle at an altitude of $590 \mathrm{~km}$. GLAS provides laser footprint geolocation and surface elevation above ellipsoid with a dedicated algorithm after corrections for tides and atmospheric effects (Brenner et al. 2000). Altimetry from GLAS is derived from the 1064-nm beam measurement. The laser footprint is $\sim 70 \mathrm{~m}$ and the data spacing is $\sim 170 \mathrm{~m}$. Because the laser beam suffered from technical problems, it was only turned on for short periods (typically 2-month windows twice a year). It was designed to study polar ice sheets but has also been used for lake level measurements. Thus, many authors have used ICESat products, particularly over the Tibetan Plateau. Although the satellite's repeat cycle and longevity were was not optimal for hydrology, spatial coverage was very high and had the potential to measure water level over a large set of lakes, as shown over the Tibetan Plateau where more than 100 lakes have been studied (Zhang et al. 2013; Phan et al. 2011; Kropáček et al. 2012; Song et al. 2013; Wang et al. 2013). It was also used to monitor river water level variations (Baghdadi et al. 2011; Jarihani et al. 2013). Furthermore, it ensured accuracy of up to a few centimeters due to the signal's very small footprint, and data provided by the National Snow and Ice Data Center (NSIDC) needed no additional corrections. The only 


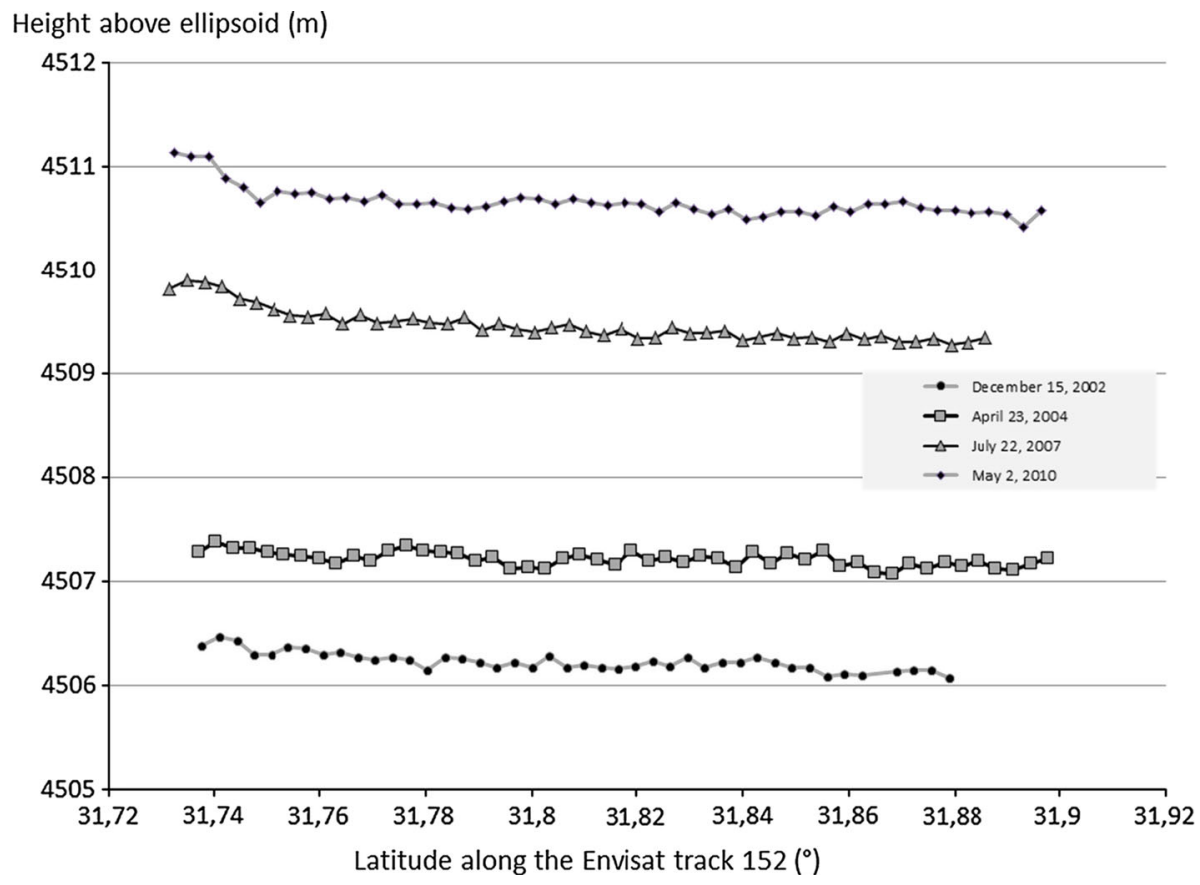

Fig. 2 Water height above the ellipsoid of reference is calculated for each individual measurement along the track at different epoch (orbital cycle). The slope along the track is calculated and used to correct each measurement in order to calculate water altitude above the geoid cycle by cycle. We used the example of Lake Ziling with Envisat track number 152 at four different dates

correction necessary was for the vertical gradients and undulations of the geoid using the same method as that described in Sect. 2.2. Launched on April 8, 2010, by ESA, the Cryosat- 2 satellite was primarily designed to study sea ice and polar ice caps. Cryosat- 2 has a 369-day repeat orbit (5344 revolutions) with an inter-track at the equator of $7.5 \mathrm{~km}$. This orbital characteristic is a real limitation for river studies, but it has some significance for lakes. First, Cryosat-2 is the first altimeter which has two antennas: an altimeter in $\mathrm{Ku}$ band which can work in LRM or SAR mode, and a second antenna which can turn the instrument to an interferometric mode called SARin. It allows precise determination of the reflecting point's geolocation within the radar footprint. Second, Cryosat-2 is of interest due to its very long repeat cycle, leading to a very short inter-track $(\sim 7 \mathrm{~km}$ at the equator and less than $6 \mathrm{~km}$ over $40^{\circ}$ latitude), and it can cover a huge number of water bodies on the Earth's surface and has the potential to measure water level changes for thousands of lakes and reservoirs worldwide. ESA provides classic GDRs of Cryosat-2 instruments for all modes of tracking (LRM, SAR, and SARin), and some authors have developed specific algorithms for them to be used over lakes (Kleinherenbrink et al. 2014) including geoid slope errors. One interest of using Cryosat-2 for lake surveys is that it also offers the possibility to fill the gap between Envisat and SARAL/AltiKa (between 2011 and 2013) and hence allows lake level variations to be calculated from the launch date of ERS2 in 1994 to the present day (see Sect. 2.4).

A new generation of altimeters has been developed by the European Space Agency and missions are being prepared for launch: Sentinel 3A for early 2016, followed by Sentinel3B scheduled for launch within the following 18 months. The altimeters onboard Sentinel- 
3A and Sentinel-3B are designed to operate in SAR mode on Ku band frequency. SAR mode will improve the ability of the altimeters to measure water level. This is particularly significant for small water bodies: straits of water like rivers, pools, artificial lakes, or reservoirs. The footprint areal extent will be reduced by a factor ranging from 10 to 50 with respect to the classical LRM altimetry mode $\left(\sim 300 \mathrm{~km}^{2}\right.$ with Jason2). Furthermore, the SAR mode will be able to redirect the measurement target point on the route. This will allow a better selection of the water body and reduce pollution from the surrounding ground signal. Therefore, it will increase the signal-to-noise ratio with regard to the LRM. In addition, the S3B/S3A tandem orbit configuration (they are operated as a couple of satellites in interleaved orbit) is particularly promising as it will allow densification of the Earth's coverage and therefore target a large number of lakes. At Legos (Biancamaria, personal communication), it has been calculated that a constellation of Jason-2, Jason-3, SARAL/AltiKa, S3A and S3B would be capable of measuring the water level for $98 \%$ of the 3720 lakes on the Earth that have an area larger than $50 \mathrm{~km}^{2}$ and $71 \%$ of the 14,411 lakes with an area larger than $10 \mathrm{~km}^{2}$. This corresponds to approximately $40 \%$ of total water storage content in lakes worldwide. This new configuration of orbit and measurement systems will significantly improve the survey of narrow tanks both quantitatively and qualitatively.

In 2020, another mission called "Jason Continuity of Service" (Jason-Cs/Sentinel-6, with the same footprint as Jason-3's (300 $\left.\mathrm{km}^{2}\right)$ ) will be set up in the same orbit. If Jason-3 is still functioning at that time, it would then be located in a different orbit, known as interleaved orbit (ground track shifted in longitude by half of its initial orbit equatorial ground track distance), resulting in double spatial coverage for each satellite. It has still not been decided whether the altimeter will be switched to SAR mode over the continent. This satellite constellation will provide a dense survey network with increased sampling time of lakes and reservoirs. Moreover, some of these instruments are now designed to survey continental water. Having different satellites will also preclude erroneous measurements from any single one of them.

However, over the next few years, the main development in this area has been the Surface Water and Ocean Topography (SWOT) which is currently under development by the National Aeronautics and Space Administration (NASA), the Centre National d'Études Spatiales (CNES), the Canadian Space Agency (CSA), and the UK Space Agency (UKSA). SWOT will carry an interferometer in Ka band that provides water elevation images for two $50 \mathrm{~km}$ swaths on either side of the satellite. Its objective is to measure water level and contour of all lakes with an area bigger than $250 \mathrm{~m} \times 250 \mathrm{~m}$ every 10 days (with a goal of $100 \mathrm{~m} \times 100 \mathrm{~m}$ ). The two swaths are separated by a band of $20 \mathrm{~km}$ without observation except along track using an additional nadir altimeter (Rodriguez 2015). The satellite will have an inclination of 77.6 degrees, and the entire emerged surface can be covered. These orbital and instrumental characteristics will allow, for example, total coverage of the Tibetan Plateau's (TP's) 1000 lakes that have an area greater than $1 \mathrm{~km}^{2}$, whereas at present the altimeters in LRM or SAR mode cover only a small proportion of them. It will also provide delineation of rivers that are broader than $100 \mathrm{~m}$ (with a goal of $50 \mathrm{~m}$ ).

The expected precision from the SWOT mission (Rodriguez 2015) is that river slope will be measured over each $10 \mathrm{~km}$ length of the rivers larger than 100 meters to $1.7 \mathrm{~cm} / \mathrm{km}$ of accuracy allowing monitoring of river discharge. Water height of lakes, reservoirs, and floodplains will be measured with $10 \mathrm{~cm}$ accuracy for $1000 \mathrm{~mm} \times 1000 \mathrm{~m}$ areas $\left(1 \mathrm{~km}^{2}\right.$ area), $20 \mathrm{~cm}$ accuracy for $250 \mathrm{~m} \times 250 \mathrm{~m}$ areas $\left(0.0625 \mathrm{~km}^{2}\right)$ and $45 \mathrm{~cm}$ for $100 \mathrm{~mm} \times 100 \mathrm{~m}$ areas $\left(0.01 \mathrm{~km}^{2}\right)$. 
The mission will provide a large range of applications for water management and the scientific study of hydrology and once the majority of the Earth's lakes, reservoirs, and rivers have been mapped every 10 days by SWOT many components of the water cycle can be measured, for example, global discharge of rivers to the ocean, water storage changes in natural and artificial reservoirs, and floodplain dynamics. When the 3-year mission is completed, the seasonal global water cycle can then be measured by SWOT and the data assimilated into models. Our knowledge gap regarding lakes and reservoirs in particular is expected to be vast (Biancamaria et al. 2010; Lee et al. 2010; Bates et al. 2014). For example, the mission will allow us to control inflow and outflow discharge for each reservoir (worldwide). Thus, the major advantage of this unique and dedicated mission will be the possibility to propose an independent, reliable, and accurate measurement system of diverse parameters to water management authorities and scientists. This could allow greater control over flow, use, and water storage availability over an entire basin (Cretaux et al. 2015).

\subsection{Combination of Multi-Satellite Data}

In many cases a lake can be covered by the tracks of different satellites, sometimes with overlapping periods and sometimes without a common period of observation. The main advantage of this is the possibility to perform a multi-satellite data processing approach for a lake's water height variations over a long period of time. For example, Lake Ziling was observed by ERS2, Envisat, SARAL/AltiKa, ICESat, and Cryosat-2 satellites from 1994 until 2015. In this framework, the use of ICESat and Cryosat-2 data was fundamental since they allow calculating relative biases between each of the missions. The calculated water level time series from each satellite are biased for two main reasons: First, there is an instrumental bias of each altimeter: This is well documented in the literature (Bonnefond et al. 2010; Mertikas et al. 2010). The second reason is that the geoid variations over a lake are not precisely known on a short wavelength of several kilometers, and as the tracks are not located exactly over the same region of a given lake, it adds a relative bias between each time series obtained from individual altimeter (Cretaux et al. 2013a; Cheng et al. 2010).

Both errors are added together, which requires some a priori adjustment of inter-track and inter-satellite biases. When only one satellite crosses a lake, even with several tracks, the geoid slope is calculated using all existing data along the track one by one and are then averaged. As tracks do not pass at the same date over the lake, the date of reference of each lake level product in Hydroweb is calculated as the barycenter of the time of each pass.

If the lake is below the orbit of several satellites, it is therefore necessary to adapt the data processing to determine the relative biases over each lake in order to calculate water level variations from multi-satellite data sources. The calculation is done in Hydroweb in a three-step process.

- Time series of each satellite is calculated independently as described above in Sect. 2.2

- Relative bias is calculated during the overlapping period

- Each bias is then removed to the individual time series, and the long-term time series is calculated at the last step.

An example is given in the figures below. For Lake Ziling (Fig. 3, 4) we can see that from the first measurements obtained with ERS-2 data to the last measurements obtained with Saral-AltiKa, the use of ICESat and Cryosat-2 has allowed us to link each of the five time series obtained independently, and to fill the gap between two alike missions such as 


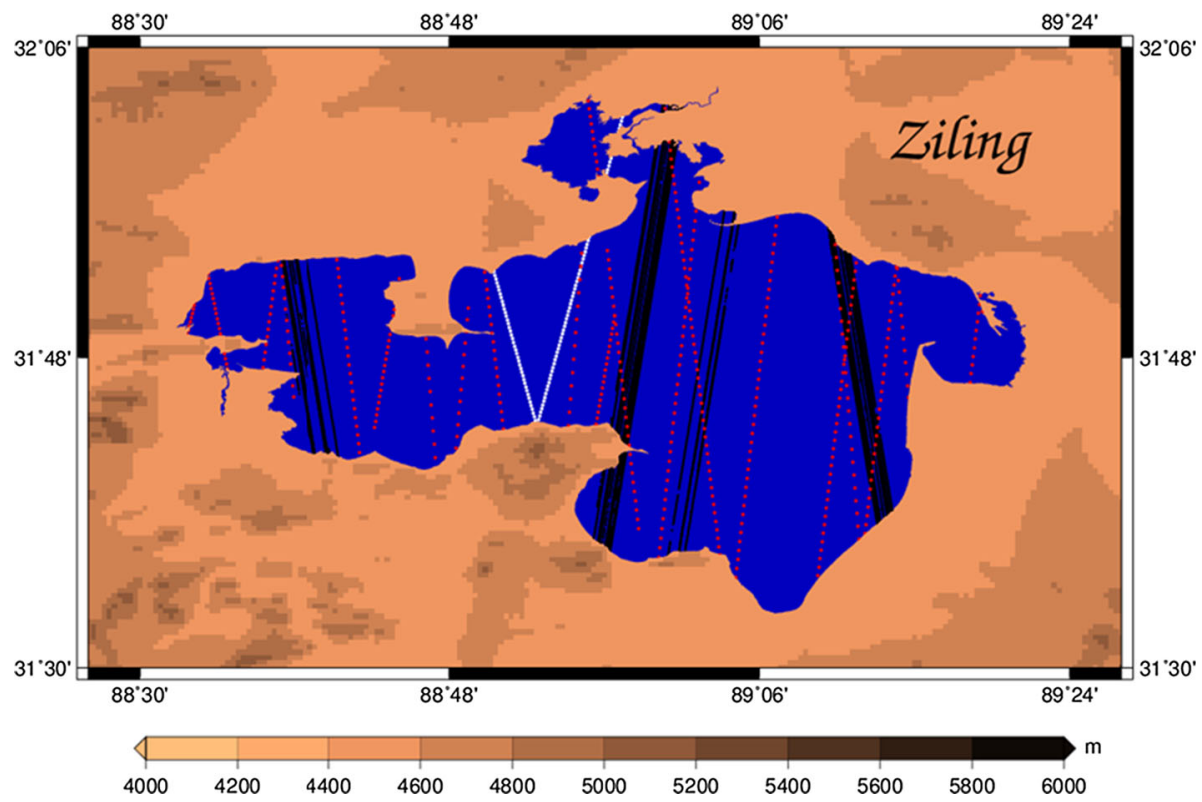

Fig. 3 Map of Lake Ziling. White lines represent the ERS2, Envisat, and SARAL/AltiKa tracks, red lines the Cryosat-2 tracks and black lines the ICESat tracks

Envisat and SARAL/AltiKa. ICESat data used for this computation was the GLA06 v33 global elevation product distributed by the NSIDC, and the Cryosat-2 data over the Tibetan plateau was turned to SARin mode. The relative biases range from a few meters to a few centimeters. The resulting 20-year time series of Lake Ziling is given in Fig. 15e.

In the next example, we present the results of calculations over Lake Ngoring-co. For this lake, seven satellites were used: T/P, Jason-1, Jason-2, ERS2, Envisat, SARAL/AltiKa, and Cryosat-2 (Fig. 5). Using all of them after relative biases correction allows us to determine lake level variations over the period 1993-2015, hence more than 20 years. This is the only way that we can examine the impact of climate change on lakes like this. Note that none of the satellites could individually capture the complex inter-annual variability of this lake. This is important to note because it is not characterized by a long-term trend but by abrupt changes followed or preceded by relatively stable lake level change or a slight trend over a few years (Fig. 6).

\subsection{Accuracy of Satellite Altimetry Over Lakes}

Over the Great Lakes (area $>100 \mathrm{~km}^{2}$ ), it has been shown (Ričko et al. 2012) that the accuracy of satellite altimetry can reach values as low as $5 \mathrm{~cm}$. However, pertaining to narrow reservoirs that accuracy may vary from $10 \mathrm{~s} \mathrm{~cm}$ to $1 \mathrm{~m}$. For example, comparisons of altimetry products with in situ daily gauge data show that the RMS accuracy ranges from a minimum of $3 \mathrm{~cm}$ for Lake Issykkul, 5-10 $\mathrm{cm}$ for the Great Lakes (Superior and Erie), to a maximum of $80 \mathrm{~cm}$ for the smaller Lake Powell (Ričko et al. 2012). The results of these analyses demonstrate the absolute need to make careful comparisons between the lake levels inferred from in situ and satellite altimetry. However, it is difficult to determine the direct relationship between lake size and the accuracy of altimetry products. 


\section{Lake Ziling}

Estimation from multi satellites data processing before biases estimation

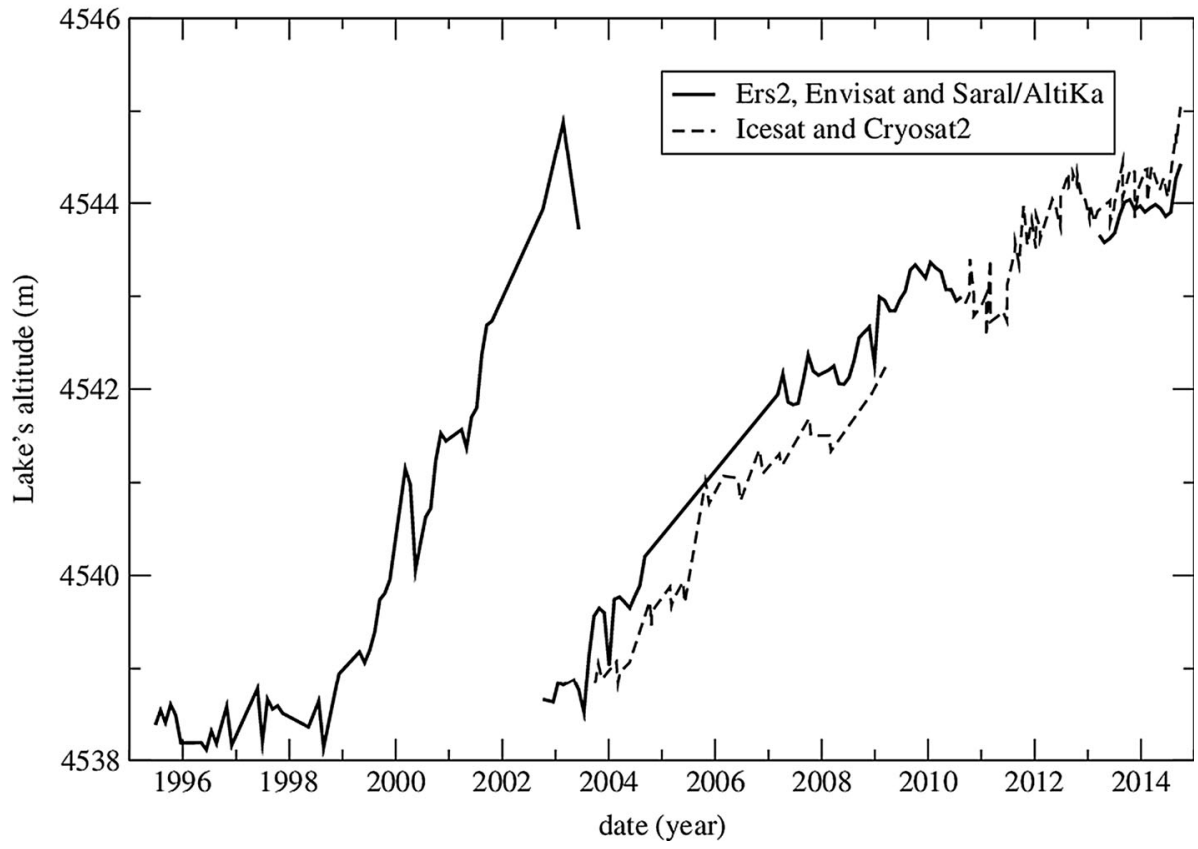

Fig. 4 Satellite altimeters over Lake Ziling from different satellites before adjusting for relative biases

The accuracy of lake height measurement depends on several factors: range, orbit, and correction errors. Range errors result from surface roughness and quality of the retracking of the altimeter waveform. It is also important to emphasize that the altimeter measurement is an average over the footprint which intrinsically differs from a singlepoint measurement of a ground gauge and which is furthermore generally done along the coast line (Table 1).

Table 2 summarizes the measurement accuracy for a set of 24 lakes of various sizes and located in different regions. We have compiled some published results with new calculations using in situ measurements collected either on the web, or from direct collaboration. The idea was to address the recurrent question concerning accuracy of altimetry for lakes and rivers and its dependency on the size of the water bodies. Is there a minimum size and anything under which the altimeter does not provide valid water levels? The results given in Table 2 clearly show that for big lakes the accuracy is largely subdecimeter and that lake size influences the quality of the results. But the results show that accuracy is also dependent on the lake's environment: mountain lakes (Argentino, General de Carrera), or those with ice and snow in winter (Onega, Athabasca); obviously, large but narrow reservoirs (Mead, Powell) have degraded accuracy. For Lake Onega, for example, we calculated the accuracy in all but the winter season, and the RMS was twice as good as that over the whole year.

In a recent study (Arsen et al. 2015) the authors quantified the improvement in accuracy when using the SARAL/AltiKa measurements over mountain lakes in regard to the results 


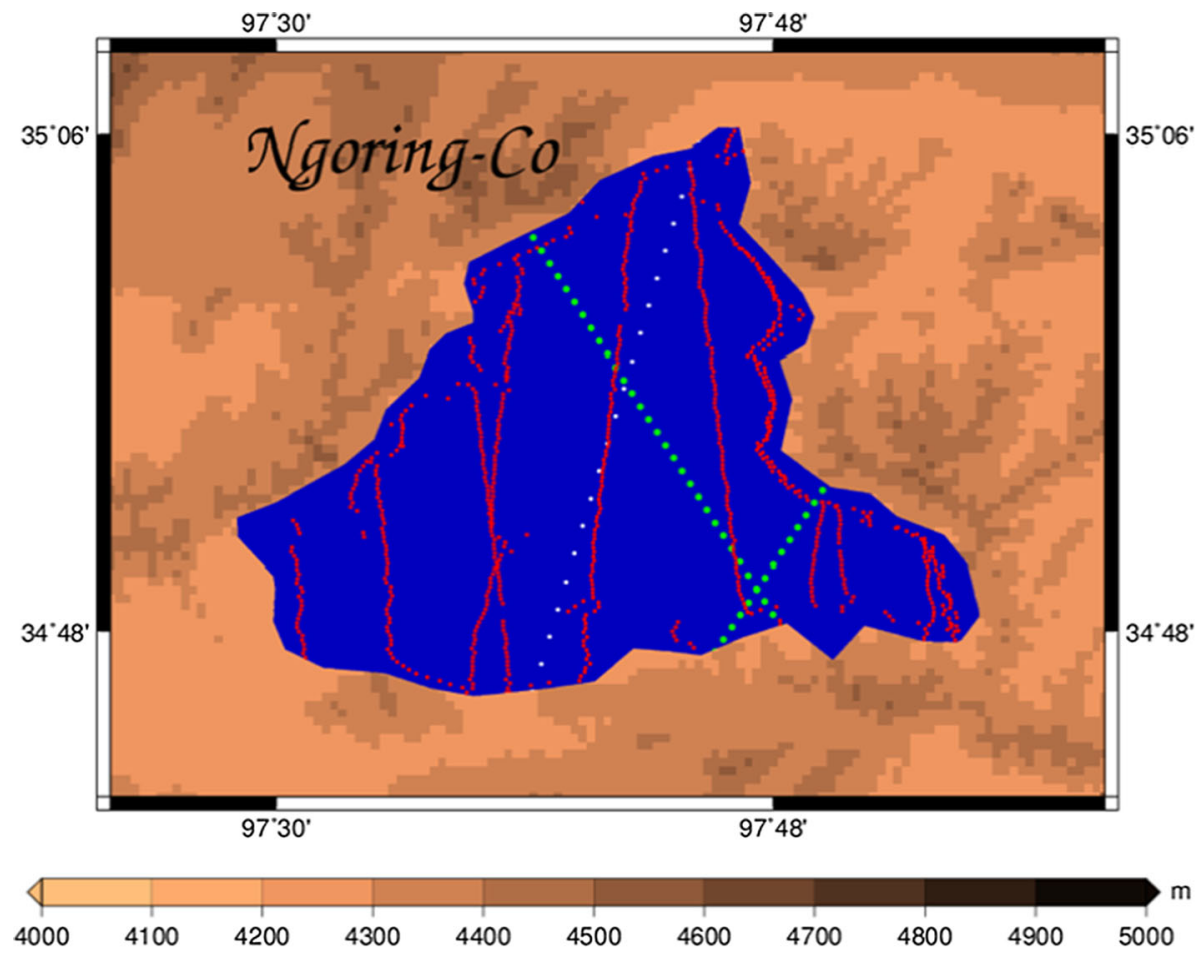

Fig. 5 Map of Lake Ngoring-co. White lines represent the ERS2, Envisat and SARAL/AltiKa tracks, red lines the Cryosat-2 tracks and black lines the ICESat tracks. Cryosat-2 measurements, in contrast to other missions, do not follow a straight line along the track of the satellite since the SARin measurements are selected for the TP. The SARin mode which uses Cryosat-2 two antennas to form a cross-track interferometer allows precise determination of the reflecting point within the footprint

obtained with Envisat. Their results were classified with respect to the length of the effective track over a given lake instead of using lake size as comparison criteria. The study was performed for 15 lakes in the Andean chain and results show that with Envisat there is a clear dependency of the RMS in terms of length of the effective track over the lake, while it was unquestionably not the case with SARAL/AltiKa. An order of magnitude of accuracy improvement with SARAL/AltiKa was calculated: For the 15 lakes, the RMS had an approximate average of $10 \mathrm{~cm}$, while it was 1 meter or sometimes more with Envisat. With its smaller footprint than Envisat, the SARAL/AltiKa measurements still had an RMS of 10-12 cm (Arsen et al. 2015).

\section{Satellite Imagery}

Satellite altimetry is used to calculate water height variations over a lake. However, this is not sufficient when the goal is to establish water balance of a lake which is preferentially represented by the water storage changes. To determine the absolute water volume of a lake is impossible without precise bathymetry (Crétaux et al. 2005; Lei et al. 2014; Song et al. 2014a, c). However, the determination of absolute water volume of a lake is not 


\section{Lake Ngoring-co}

Estimation from multi satellites data processing

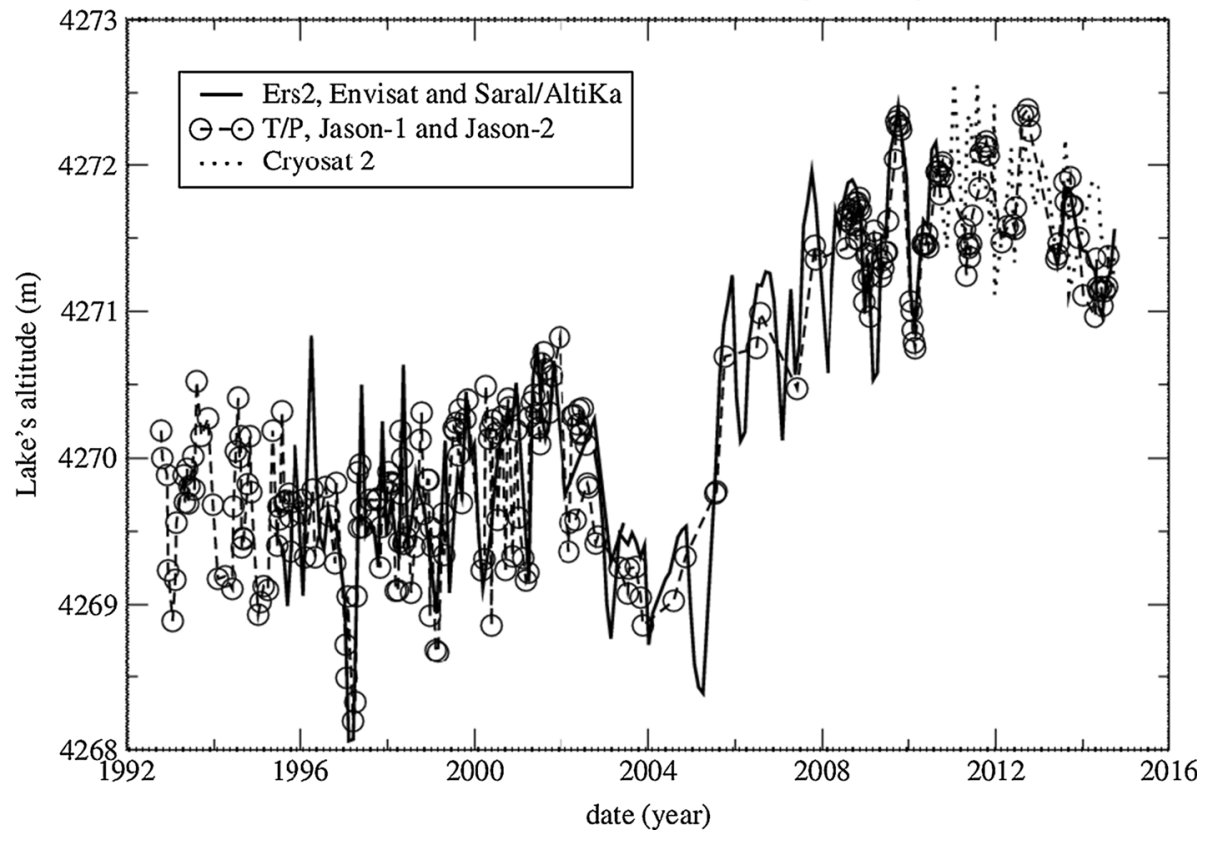

Fig. 6 Combination of data from several satellite altimeters over Lake Ngoring-Co after the adjustment of relative biases

fundamental when it is easier to calculate volume variations. To perform this variable, we can use a combination of a lake's water height and water surface extent at different dates and then establish a relationship between these variables and water volume changes. This calculation has been used in many published studies (for an example see Gao et al. 2012; Duan and Bastiaanssen 2013; Arsen et al. 2014). The first step relates to using satellite imagery to compute several lakes' water mask therein corresponding to concomitant water heights. However, the methodology to extract water mask from satellite imagery is not straightforward and is why there is a description below. The Hydroweb database uses this approach to determine the water surface of Tibetan lakes and other lakes throughout the world.

Many methods exist for the extraction of water surface from satellite imagery, which, according to the number of bands used, are generally divided into single-band and multiband methods. Using the simplest approach, a single band is selected from a multi-spectral image and used to extract water surface information. In practice, both the surface reflectance and satellite digital numbers are used to calculate vegetation cover or water extent (Crétaux et al. 2011b). The second category takes advantage of reflective difference in each multi-spectral band. Spectral signature analysis of water among different bands can be made, and tree methods can be used to delineate water surface or other features. Commonly used methods are based on an index, which combines a multi-band ratio of visible red/green and near-infrared (NIR)/short-wave infrared (SWIR) bands. Then, the water mask is derived from thresholding the chosen index (regions with an index above the given 
Table 1 List of past and future missions used in Hydroweb with their general characteristics

\begin{tabular}{llllll}
\hline Mission & Agency & Frequency & Mode & Time (year) & Cycle (day) \\
\hline T/P & NASA/CNES & Ku & LRM & $1992-2005$ & 10 \\
Jason-1 & NASA/CNES & Ku & LRM & $2002-2011$ & 10 \\
Jason-2 & NASA/CNES & Ku & LRM & 2008 -present & 10 \\
Jason-3 & NASA/CNES/EUM & Ku & LRM & 2015 & 10 \\
& ETSAT/NOAA & & & & \\
Jason-Cs & NASA/CNES/EUME & Ku & Not decided yet & 2017 & 10 \\
& TSAT/NOAA/ESA & & & & \\
GFO & NRL & Ku & LRM & $2002-2008$ & 17 \\
ERS-2 & ESA & Ku & LRM & $1995-2002$ & 35 \\
Envisat & ESA & Ku & LRM & $2002-2011$ & 35 \\
SARAL/AltiKa & CNES/ISRO & Ka & LRM & 2013 -present & 35 \\
Sentinel-3A & ESA & Ku & SAR & 2015 & 27 \\
Sentinel-3B & ESA & Ku & SAR & 2016 & 27 \\
CryoSat-2 & ESA & Ku & LRM/SAR/SARin & 2010 -present & 369 \\
ICESat-1 & NASA & Laser & LRM & $2003-2009$ & 91 \\
ICESat-2 & NASA & Laser & LRM & 2017 & 91 \\
SWOT & NASA/CN & Ka & SAR & 2020 & 21 \\
& ES/CSA/UKSA & & & & \\
\hline
\end{tabular}

threshold are classified as water). Different indexes have been proposed in the literature. The Normalized Difference Water Index (NDWI) was first introduced by McFeeters (1996) and expressed as the band ratio:

$$
\mathrm{NDWI}=\frac{-\mathrm{NIR}}{\text { Green }+\mathrm{NIR}}
$$

Xu (2006) proposed Modified Normalized Difference Water Index (MNDWI) expressed as the band ratio:

$$
\text { MNDWI }=\frac{- \text { MIR }}{\text { Green }+ \text { MIR }}
$$

For convenience, we label indexes that use green and NIR as NDWI $\mathrm{L}_{\mathrm{L} / \mathrm{M} \text { : Green, NIR and }}$

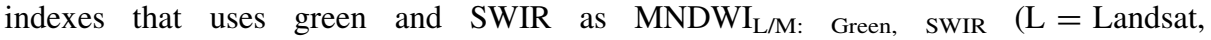
$\mathrm{M}=$ MODIS), where Green can be the Landsat TM/ETM + band 2 (520-600 nm) or MODIS band 4 (545-565 nm), and NIR as Landsat TM/ETM + band 4 (750-900 nm) or MODIS band 5 (1230-1250 nm). Similarly, MIR (or SWIR) can be mid (short)-infrared bands such as Landsat TM/ETM + band $5(1550-1750 \mathrm{~nm})$ or MODIS band 6 $(1628-1652 \mathrm{~nm})$. Many other formulations of spectral band ratios can also be found in different combinations of visible or infrared bands (Ji et al. 2009). Boschetti et al. (2014) provide a useful and coherent review of existing water indices and their application for water detection. From band ratio histograms, different objects can be separated from their background with a simple threshold method (Otsu 1979). Computing the previously described indexes is relatively easy. However, choosing the adequate threshold value to compute the water mask can be very tricky because of two major issues. First, band ratios calculated from different band combinations necessarily have different threshold values for 
Table 2 Comparison (RMS and $R^{2}$ ) of average water level from satellite altimetry (available on Hydroweb database) for a set of 24 lakes of various location and size where in situ measurements are available from different sources

\begin{tabular}{|c|c|c|c|c|c|}
\hline Lake name & Continent & Area $\left(\mathrm{km}^{2}\right)$ & Period & RMS (cm) & $R^{2}$ \\
\hline Argentino $^{1}$ & South Am & 1466 & 1992-2011 & 22 & 0.96 \\
\hline Athabasca ${ }^{2}$ & North Am & 7900 & 1992-2009 & 28 & 0.91 \\
\hline Aydarkul $^{3}$ & Asia & 3000 & $2002-2010$ & 12 & 0.95 \\
\hline Baikal $^{4}$ & Asia & 31,500 & 1992-2009 & 11 & 0.94 \\
\hline Bratsk $^{4}$ & Asia & 3100 & 1992-2009 & 41 & 0.98 \\
\hline Erie $^{2}$ & North Am & 25,800 & 1992-2011 & 10 & 0.95 \\
\hline Guri $^{2}$ & South Am & 3500 & 2002-2010 & 82 & 0.99 \\
\hline General Carrera $^{1}$ & South Am & 1850 & 2002-2010 & 22 & 0.90 \\
\hline Huron $^{2}$ & North Am & 59,570 & 1992-2011 & 8 & 0.99 \\
\hline Issykkul $^{6}$ & Asia & 6000 & 2002-2014 & 3 & 0.99 \\
\hline Khanka $^{4}$ & Asia & 4400 & $2000-2010$ & 13 & 0.6 \\
\hline $\operatorname{Ladoga}{ }^{4}$ & Europe & 18,135 & 1992-2010 & 8 & 0.98 \\
\hline $\operatorname{Mead}^{5}$ & North Am & 350 & $2001-2010$ & 64 & 0.99 \\
\hline Michigan $^{2}$ & North Am & 58,000 & 1992-2011 & 11 & 0.98 \\
\hline Oahe ${ }^{6}$ & North Am & 700 & $2002-2010$ & 45 & 0.99 \\
\hline Onega $^{4}$ & Europe & 18,200 & $1992-2010$ & 15 & 0.88 \\
\hline Ontario $^{2}$ & North Am & 19,000 & 1992-2011 & 6 & 0.98 \\
\hline Powell $^{5}$ & North Am & 400 & 1992-2010 & 85 & 0.99 \\
\hline Superior $^{2}$ & North Am & 82,200 & 1992-2011 & 6 & 0.97 \\
\hline Tana $^{2}$ & Africa & 3000 & 1992-2006 & 17 & 0.97 \\
\hline Tchad $^{2}$ & Africa & 1540 & 1992-2008 & 28 & 0.91 \\
\hline Titicaca $^{7}$ & South Am & 7800 & $2000-2005$ & 7 & 0.99 \\
\hline Volta $^{2}$ & Africa & 8500 & 1999-2010 & 53 & 0.98 \\
\hline Woods ${ }^{2}$ & North Am & 4350 & 1992-2011 & 27 & 0.81 \\
\hline
\end{tabular}

\footnotetext{
1 Subsecretaría de Recursos Hídricos (www.hidricosargentina.gov.ar)

2 From Ričko et al. 2012

3 From www.cawater-info.net

4 In situ data from State Institute of Hydrology of St Petersburg, Russia

${ }^{5}$ United States Bureau of Reclamation

${ }^{6}$ In situ data from the Institute of Water Problems, Bishkek

7 Personal communication from J-L Guyot (source: Institute of Hydrology, Peru)
}

the same feature. Thus, a unique threshold cannot be applied to a multi-satellite study. Additionally, optical properties of surface objects vary with time due to factors such as varying Sun-target-satellite geometry, atmospheric or soil conditions, water turbidity, sediment load, and sensor degradations. Liu et al. (2012) have proved that small threshold variations can occur even on a daily basis. Secondly, band ratio threshold varies depending on the proportion of sub-pixel water/land/vegetation components. Mixed pixels are especially important for coarse resolution satellite images [SPOT VEGETATION $(1 \mathrm{~km})$, and MODIS $(250 / 500 \mathrm{~m})$ ] because large pixels usually have complex combinations of water/land cover types within the pixel area. Several studies investigated the issue of the 
optimal band combination to best delineate water features. $\mathrm{Xu}$ (2006) found that the $\mathrm{NDWI}_{\mathrm{L} 2,4}$ (McFeeters 1996) was unable to completely discriminate buildup from water features and have proposed $\mathrm{MNDWI}_{\mathrm{L} 2,5}$. Ji et al. (2009) evaluate mixture pixel impacts on simulated spectral bands of Landsat ETM+, SPOT, ASTER, and MODIS and recommend $\mathrm{MNDWI}_{\mathrm{M} 4,5}$ and $\mathrm{MNDWI}_{\mathrm{L} 2,5}$ for use in mapping surface as the less affected by sub-pixel vegetation components. Ouma and Tateishi (2006) tested five different forms of band ratios for water body delineation including $\mathrm{NDWI}_{\mathrm{L} 2,4}$ and $\mathrm{MNDWI}_{\mathrm{L} 2,5}$. They ranked $\mathrm{NDWI}_{\mathrm{L} 2,4}$ as second and $\mathrm{MNDWI}_{\mathrm{L} 2,5}$ as third in order of best performance. In a more recent study Boschetti et al. (2014) compared performances of several MODIS band ratios and recommended the combination of $\mathrm{MNDWI}_{\mathrm{M} 4,6}$ as the best for pure water pixel detection. These studies show that, depending on the instrument used and specific conditions of the study zone (water turbidity/depth, percentage of water present in the pixel), one combination of bands can outperform another. Therefore, it is necessary to validate the results with ground observations if available, but even then, final conclusions will depend on the methodology employed and the study zone delineation. Although interesting conclusions can be found among previously cited publications, only a few of them offer real examples of band ratio thresholds (e.g., Sakamoto et al. 2007). The subjective selection of the threshold value may lead to an over- or underestimation of open water area. We use one example to illustrate the difficulties in threshold selection. In Fig. 7, several grounds to water intersection profiles are shown for Lake Zhari Namco in the Tibetan Plateau $\left(30^{\circ} 55^{\prime} \mathrm{N} 85^{\circ} 38^{\prime} \mathrm{E}\right)$. They represent $\mathrm{NDWI}_{\mathrm{L} 2,4} / \mathrm{MNDWI}_{\mathrm{L} 2,5}$ values calculated with Landsat 5TM, 7ETM+, and Landsat 8 OLI at different dates. The profiles start over a small 2- to 3-pixel-wide water pond and pass over the lake's surface. We can see on MNDWI profiles
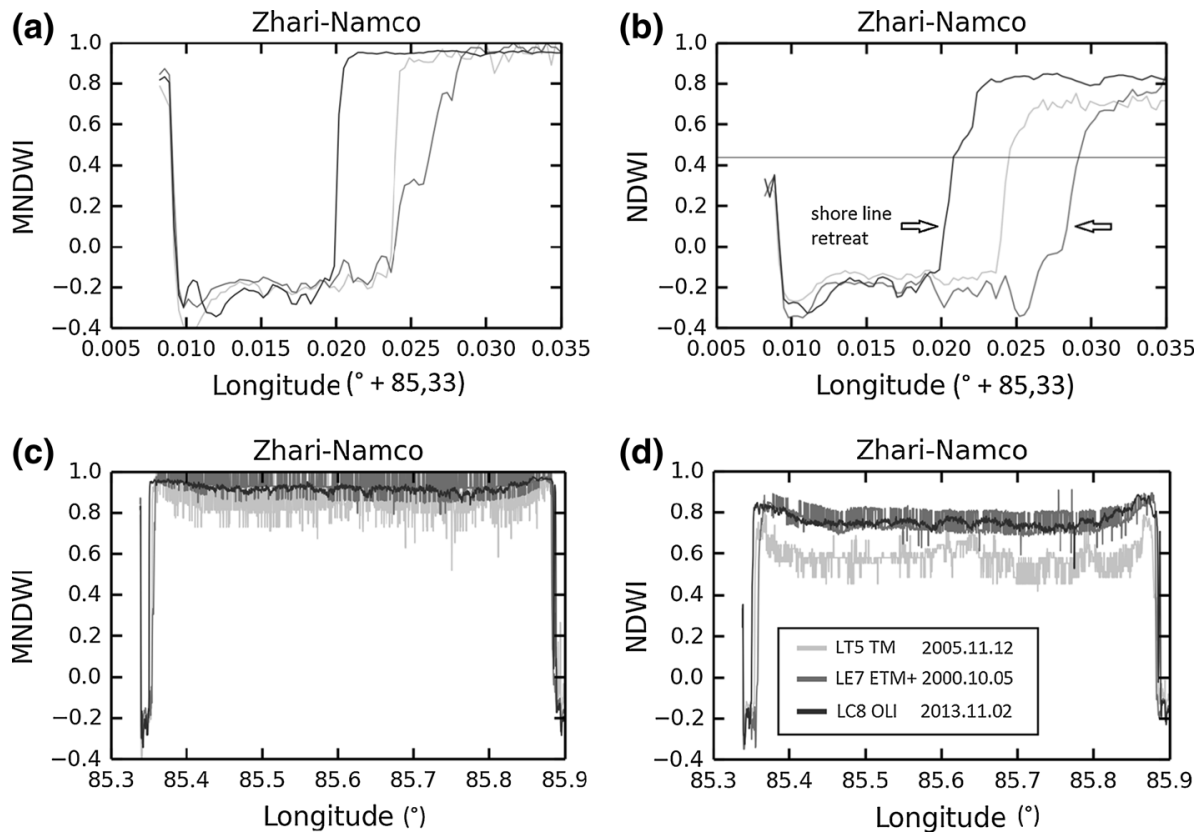

Fig. 7 Methods of water pixel mapping with MNDWI for the Lake Zhari Namco near the shoreline using Landsat images (a), with NDWI (b), and longitudinal profiles across the entire lake for MNDWI (c) and for NDWI (d) 
(Fig. 7a) that the land/water crossing has very strong signatures for both the lake and the water pond. The small water pond composed of mixed pixels has a much weaker response on NDWI (Fig. 7b). Indeed, Xu (2006) has proved that the detection of mixed pixels is easier with MNDWI. However, the strong response of mixed pixels reduces the gap between maximal values and makes the differentiation between open water and mixed pixels more difficult. The land/water crossings of NDWI profiles are composed of several lines with different slopes. A particular region can be located around 0.42 on LC8 OLI 2013.11.02 profile (Fig. 7b). The value 0.42 NDWI (0.44 MNDWI) has been calculated by $\mathrm{Xu}(2006)$ as the mean value which characterizes the open water surface of Lake Bayi. We can see the same transition on two others profiles. Figure $7 \mathrm{c}, \mathrm{d}$ represents longitudinal profiles of MNDWI/NDWI across the entire Lake Zhari Namco. One can immediately notice that NDWI/MNDWI values in the middle of the lake have lower values than near shore, which is due to partial transparency of water near shore. We also notice a highfrequency noise from artifacts on Landsat $5 \mathrm{TM}$ and 7ETM+ images owing to sensor degradation. The mean values of MNDWI and NDWI vary in time and are the lowest for the 2001 image. The 2006 profile has much higher mean value, and thus we can attribute these changes to temporal variations in air aerosols and water turbidity rather than sensor degradation. A fixed threshold of 0.9 on the MNDWI deduced from near shore values could simply be used if the objective is to map only water pixels (Fig. 7a).

However, in this case, taking a lower MNDWI threshold will automatically include all mixed pixels in our estimations. With a fixed threshold of 0.4 NDWI, it can then be possible to map open water pixels of Lake Zhari Namco in all three cases. From our experience, the use of MNDWI or NDWI clearly depends of the study zone. Most of the lakes can be accurately mapped with NDWI. In some cases the use of MNDWI may be also interesting. Within the Hydroweb database, the areal extent, i.e., surface time series, may vary slightly from other studies. This situation is perfectly understandable. As there is no clear definition of where a lake starts or ends, each author is able to perform their own delineation. However, the discrepancy between results may increase due to low-resolution bias. Low-resolution bias is the inaccuracy introduced by the differences in spatial resolution between high and low-resolution data (Boschetti et al. 2014). This surface bias must be estimated in order to properly translate results obtained with one resolution to another (e.g., Arsen et al. 2014). For the Hydroweb database, the hypsometry of lakes is estimated with no more than 10-15 images (information given).

In the frame of Hydroweb, the following steps are used in Landsat image processing:

- Overview of study zone before delineation. Several factors should be estimated: minimum and maximum water extent, appearing/disappearing islands, flooding areas, the presence of vegetation/aquatic vegetation components, and in situ data availability.

- Image selection. If possible strictly limited to cloud free, ice-free and inundation-free scenes in order to reduce difficulties in interpretation.

- Definition of region of interest (ROI) based on maximum and minimum water extension, cutoff of unnecessary parts (mountains, rivers) to reduce difficulties in interpretation, and safety margin for water rise.

- For each image: conversion of digital number (DN) in each spectral band to surface reflectance using the calibration coefficients provided in the image's metadata including latest sensor degradation studies. Atmospheric corrections such as dark object subtraction (Chavez 1989, 1996) are optional and mostly required for vegetation change mapping (Song et al. 2011).

- For each image: MNDWI and NDWI generation. 
- The water surface is calculated for all open water pixels starting from an initial value of NDWI $\geq 0.4$. Statistical study of histogram profiles at ground/water intersection can be used for manual adjustments of the threshold to ensure a coherent and well distinguished shoreline. Water class is constant during the study. This guarantees that mixed pixels are selected in exactly the same manner. Underestimations of NDWI will be corrected with supervised methods.

- For each image: thresholding of NDWI or MNDWI, generation of snapshots, subsets, and ROI files. Overview of results and supervised corrections of: extra thin cloud strips, inclusions (ice or clouds), sensor artifacts, algae or vegetation blooms, and other underestimations.

For more information about satellite image data processing, we recommend the processing guideline proposed by $\mathrm{Ji}$ et al. 2009.

Consequently, in Hydroweb we first use the water level time series inferred from satellite altimetry in order to determine some key periods when the lake was at extreme height and some intermediate values in order to select satellite imagery at those dates. It is not realistic to determine water extent of a lake for each measurement of its water level, especially when a lake is too large and is not covered by only one image.

We used Landsat 7 ETM+ and Landsat 5 TM images (available on the USGS GLOVIS image archive (http://www.gloviusgs.gov/) and when the spatial resolution was not necessarily high MODIS images (500 m of resolution, MOD09GHK products) were also selected. In general, we try to select between 10 and 15 images at different dates and calculate the hypsometry relationship $(\mathrm{dA} / \mathrm{dH})$, where $\mathrm{A}$ is the lake area (in $\mathrm{km}^{2}$ ) and $\mathrm{H}$ is the height of the water surface above the geoid (in $\mathrm{m}$ ), which is then applied to determine surface extent of the lakes each time a water level is calculated using satellite altimetry. The hypsometry is expressed as a polynomial of degree 1,2 or 3 depending on the linearity of the couples of water level and surface extent of the lake. In such processing, we do not need to process a large amount of satellite images, and this is a practical way to deliver through Hydroweb time series of lake surface extent together with height time series.

\section{Storage Change Calculation}

The determination of volume variations is done under the hypothesis that between two successive measurements (at date $T_{0}$ and $T_{1}$ ) of the couple, $A$ and $H$, the morphology of the lake is regular and has a pyramidal shape (Abileah et al. 2011), and we can therefore derive the water volume changes from the following equation:

$$
\Delta V=\frac{(H 1-H 0) \times(A 1+A 0+\sqrt{A 1 \times A 0)}}{3}
$$

where $\mathrm{V}$ represents the volume variation between two consecutive measurements, $\boldsymbol{H 1}, \boldsymbol{H O}$ and $\boldsymbol{A 1}, \boldsymbol{A O}$ are levels and areal extents at date $\boldsymbol{T}_{\mathbf{1}} / \boldsymbol{T}_{\mathbf{0}}$, respectively. Figure 8 gives an example on Lake Ayakkum located in the northern part of the TP with a two-order polynomial fit of area versus height of the lake.

From Fig. 9 above it is interesting to note that the hypsometry of a lake is not always linear. This implies that, in Hydroweb, we consider the polynomial coefficient to determine surface variation from height variations only in the domain of validity of the hypsometry, so we don't extrapolate the water surface for water height outside of the maximum and minimum values used to determine polynomial coefficients. As a comparison, in Song et al. (2013) the same 
Ayakkum

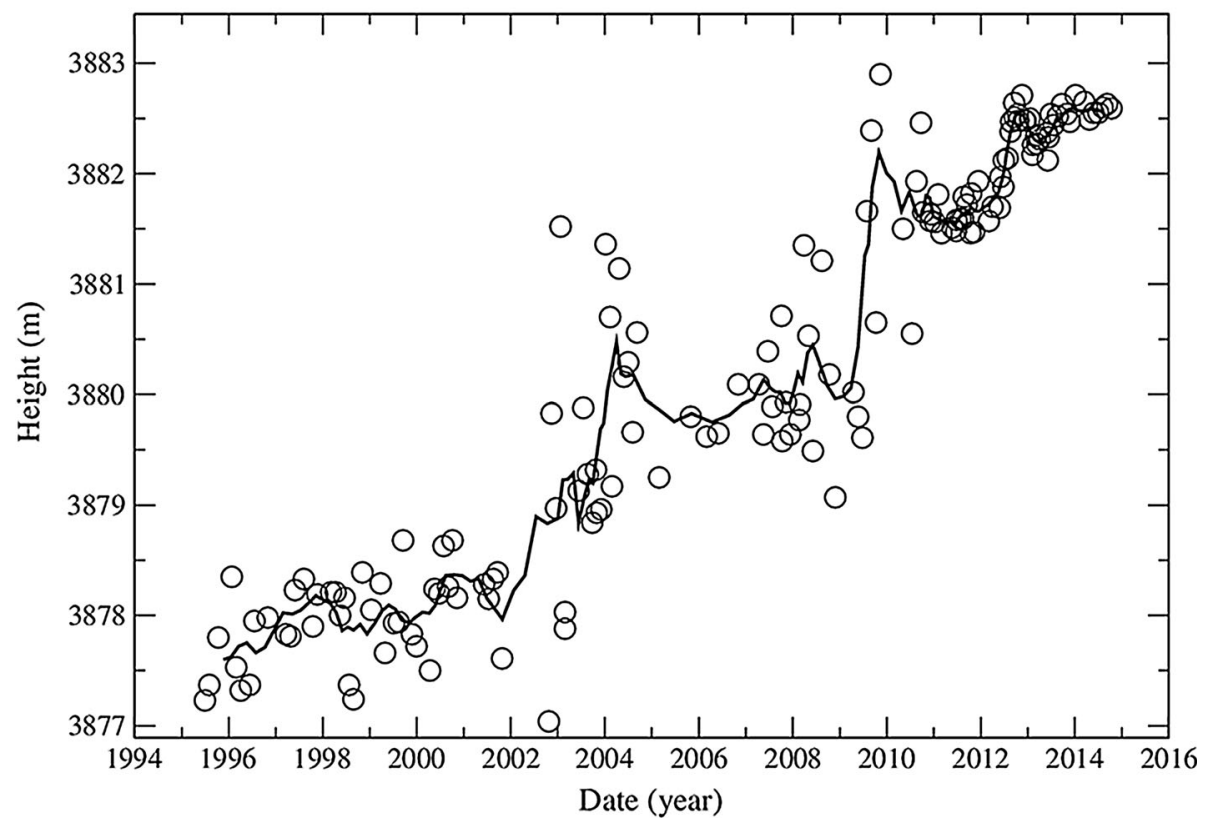

Fig. 8 Lake Ayakkum's height from multi-satellite altimetry (ERS2, Envisat, CryoSat-2, and SARAL/ AltiKa). The circles represent individual measurements and the black line a moving average done over every six individual measurements

calculation was made for a set of 12 Tibetan lakes, and we see that for Lake Ayakkum they established a linear function of area versus height (Area $=89.2857 \times$ height -345602$)$ because only ICESat data from 2003 to 2009 was used, which could lead to some errors in water surface extrapolation for similar cases. Indeed, for a low lake water height of $3880 \mathrm{~m}$, the two sets of polynomial coefficients both give an area of about $820-830 \mathrm{~km}^{2}$. In contrast, for a high lake water height of $3882 \mathrm{~m}$ (reached in 2011-2012), the second-order polynomial development leads to $896 \mathrm{~km}^{2}$, while in Song et al. (2013) with a one-order polynomial development, it reaches more than $1000 \mathrm{~km}^{2}$.

In Hydroweb, the time series for about 20 lakes of the Tibetan Plateau are given for these three variables, $\mathrm{H}, \mathrm{A}$, and $\mathrm{dV}$ over at least one decade. We use the multi-satellite approach which is described in Sect. 2.4. The data from ERS2, T/P, Jason-2, Envisat, ICESat, Cryosat-2, and SARAL/AltiKa have been used to perform the calculation of water level variations of these lakes. We therefore provide long decadal time series for some of these lakes, and we show in the next section the results obtained for a list of 11 large lakes in the southern TP, with the majority of them having more than 20 years' worth of data.

\section{Case Study: The Tibetan Plateau}

The Tibetan Plateau is the largest and highest region on Earth and the source of 10 major river systems that provide irrigation, power and drinking water for over 1.3 billion people-nearly $20 \%$ of the world's population—and is known as the "water tower of Asia." 


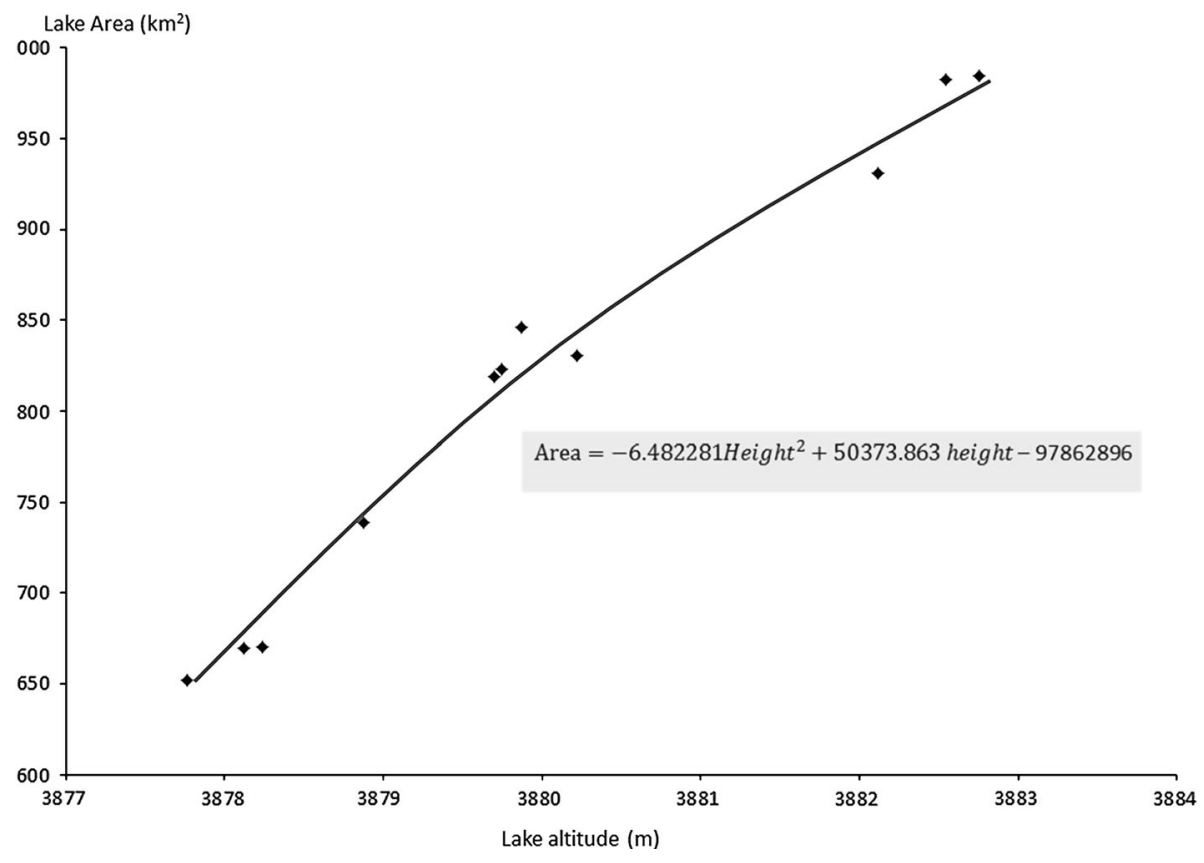

Fig. 9 Hypsometry polynomial of Lake Ayakkum (within the hypsometry equation, height is expressed in meters and area in $\mathrm{km}^{2}$ )

The TP is considered as one of the most sensitive regions on Earth to global warming (Yao et al. 2012) and therefore plays a key role on both hydrology and climate for southern and eastern Asia. Its ice fields contain the largest reserve of fresh water outside the polar regions. It has been named The Third Pole. It has an average altitude of $4000 \mathrm{~m}$ a.s.1 and is covered by mountains, glaciers, high altitude plateaus, permafrost, and hundreds of lakes (Liu and Chen 2000; Liu et al. 2009a; Huang et al. 2011; Wan et al. 2014; Zhang et al. 2015).

Its climate is very dry in the northwest (50 mm/year of rainfall) and more humid in the Southwest $(700 \mathrm{~mm} / \mathrm{year})$ with more than $60 \%$ of its precipitation falling during the summertime (Kang et al. 2010). It is under the influence of the Indian and East Asian monsoon and of the westerlies ( $\mathrm{Li}$ et al. 2007). The TP has been warming over the last 50 years at a rate of $0.36 \%$ decade (Wang et al. 2008) which doubles previous estimates made by Liu and Chen (2000). This phenomenon has been more pronounced over the last 30 years, particularly in winter (Kang et al. 2010; Huang et al. 2011). Precipitation changes have strong regional patterns and high inter-annual variability. It has become wetter in the East and central part (Kang et al. 2010; Xu et al. 2008) and dryer in the Northeast and West (Huang et al. 2011; Kang et al. 2010; Xu et al. 2008).

The consequences of these climate change geographical patterns are visible on lake water balance. Some are declining, for example in the far south of the TP or near the source of the Yellow River (Huang et al. 2011). Many of the lakes in the western regions and central part of the TP and in the North are, in contrast, expanding due to the accelerated melting of glaciers and permafrost (Liu et al. 2009a; Huang et al. 2011). However, there is not always a direct relation between long-term precipitation changes and lake level 
variations (Huang et al. 2011; Zhang et al. 2011a; Liu et al. 2009a). In general, the magnitude of precipitation changes is too low to explain water level increasing a few decimeters per year as noted by Zhang et al. (2011a). The impact of climate change on water resources over the TP is therefore very complex: a mix not only of direct precipitation changes and evaporation increase under a warming climate, but also of glaciers, snow, and thickening of the active layer of the permafrost, which increase surface and underground inflow to the lakes (Ma et al. 2010; Liu et al. 2009a; Kang et al. 2010; Huang et al. 2011; Zhang et al. 2011a; Li et al. 2014; Song et al. 2014c; Zhang et al. 2015). The decrease in the frozen duration due to warming, which is very pronounced in winter time, also increases the potential contribution of permafrost to lake storage changes (Huang et al. 2011; Li et al. 2008; Liao et al. 2013). It has been observed that in some regions of the TP, the lower limit of the permafrost has risen by more than $80 \mathrm{~m}$, and the active layer has grown by a few decimeters since 1970 (Li et al. 2008), and the total permafrost extent over the TP has declined by $100,000 \mathrm{~km}^{2}$ (Kang et al. 2010). In addition, melting of massive ground ice has resulted in thermokarst ponds which, as a major heat source, speeds up the moisture change, and enhances degradation of its surrounding permafrost ( $\mathrm{Li}$ et al. 2014). This could explain the geographical disparity of lake storage changes over the TP.

There are 37,000 glaciers covering the TP, and most of them have retreated since the end of the 20th century (Neckel et al. 2014; Wei et al. 2014), directly increasing the surface water recharge to lakes and downstream rivers. The area of the TP glaciers has decreased by $7 \%$ over the last 40 years (Krause et al. 2010) and will probably continue to shrink in the future (Solomon et al. 2007). If this increases the surface water runoff at short timescale, at longer timescale a significant reduction of stream flow resulting from glaciers melting is predicted (Eriksson et al. 2009).

Many studies are now investigating the impact of melting glaciers on the water balance of lakes by using satellite remote sensing and/or models (Kang et al. 2010; Ye et al. 2007; Liao et al. 2013; Song et al. 2014c). For example, Wu and Zhu (2008) and Yao et al. (2007) explored links between area changes of glaciers in Lake Namco's watershed and its expansion in size over recent years. Ye et al. (2007) have estimated the contribution of glaciers in the water balance of Lake Yamzhog Yumco in South Tibet under expansion at the end of the last century. Phan et al. (2013) have shown that glacier melting has become an important factor of water storage change for a large number of lakes over the TP.

As essential natural resources for many different uses, lakes over the TP are therefore under increasing climate stress which needs to be quantified and understood. However, there are only a few gauging instruments (meteorological and hydrological) installed on the $\mathrm{TP}$, and the monitoring of glaciers, permafrost, regional climate change, runoff, and lake level is performed very sparsely and only in recent years. This is why the majority of studies are now based on remote sensing data, and satellite altimetry application for lakes over the TP has been widely adopted by hydrologists and climatologists.

Indeed, satellite altimetry (radar and laser) has been used to calculate water level changes of lakes over the TP. It could be focused on a specific subregion of the TP concerning an individual or limited number of lakes such as lakes Namco and Ziling that were studied in Wang et al. (2013), Li et al. (2014), Song et al. (2015), Ngoring-co by Lee et al. (2011), Liao et al. (2013), Ngangze and La'anga from Hwang et al. (2005) and many others (along with references in the papers cited before). Since 2010 several authors have studied lake level changes and their connection to climate change using satellite altimetry and/or satellite imagery as a principal source of information for the whole TP (Liu et al. 2009a; Zhang et al. 2011a; Phan et al. 2011; Huang et al. 2011; Song et al. 2014b; Kleinherenbrink et al. 2015). They generally try to describe the water level or storage 
changes of the lakes in terms of global warming and to determine which component of the water balance is the most influential.

However, nothing regarding the potential use of lakes as a climatic index at the global scale has been published so far. Many studies have investigated the correlation of lakes (mainly at local or regional scale) with climate indexes like the El Niño Southern Oscillation (ENSO), Pacific Decadal Oscillation (PDO) or North Atlantic Oscillation (NAO), but the strong potential of lakes to be considered as a proxy which may be quantified as climatic index has not yet been considered in the literature. However, Street-Perrott et al. (1986) and Mason et al. (1994) have established that lakes react as a low-pass filter to any changes in one of the components of their water budget and have defined associated equations. We will show in the following that this theory could help to interpret the water level and storage changes by using examples of lakes in the TP.

The theory of lake water balance states that a lake always evolves in a way to reach an equilibrium state where water input is equal to water output. We have calculated that Lake Namco has an equilibrium response time of 160 years, Lake Ziling 100 years, Lake Tangra Yumco more than 500 years, and Lake Ayyakum only 24 years (using equations given in Mason et al. 1994). This means that two lakes, for example, lakes Ziling and Tangra Yumco that are in close proximity to each other and with approximately the same net evaporation rate $(\mathrm{E}-\mathrm{P})$, will not react with the same temporal patterns to any changes of the evaporation rate $\mathrm{E}$ or the precipitation rate $\mathrm{P}$. It should be noted that the equilibrium response may also change if the bathymetry of a lake at different altitudes moves from a steep to shallow shoreline (or the opposite).

We calculated the equilibrium response type for different values of E-P and for different types of lakes (Mason et al. 1994). For lakes with a steep bathymetry (left part of the figure), this time is rather long and is amplified for arid lakes. For shallow lakes (right part of the figure), the relative dependency on E-P diminishes and equilibrium response time is very rapid (a few years). Thus, for a large majority of lakes on the Tibetan Plateau the time to reach equilibrium can take centuries (Figs. 10, 11, 12, 13, 14, 15).

\section{Results}

A large number of recent studies have assumed that the lakes of the TP are globally in a phase of expansion as a consequence of marked climate change observed over many years. However, the majority of these studies were based on a short time period of a few years at the beginning of the twenty-first century (Zhang et al. 2011a; Phan et al. 2011; Song et al. 2013; Wu et al. 2014). The authors have shown that between 2003 and 2009 (using ICESat data) from about 100 lakes monitored, the water height of a large proportion of them increased on average by about $20 \mathrm{~cm} /$ year. In Song et al. (2013), the authors also calculated water storage changes for a large number of lakes of the TP, but they only used ICESat data to determine the hypsometry. Their study only covered the period up to 2011. They show a general increase in water storage over the decade 2000-2011 of about $6.79 \mathrm{~km}^{3} /$ year. Although these observations are not doubted, it is premature to draw conclusions on the impact of climate warming over so short a period of time. One of the most interesting cases is regarding Lake Namco, the subject of many recent publications.

Lake Namco is located in southeastern Tibet and is one of the largest lakes of the TP with an area of approximately $2000 \mathrm{~km}^{2}$, a catchment area of $11,000 \mathrm{~km}^{2}$, and an altitude of about $4725 \mathrm{~m}$. Krause et al. (2010) calculated the water balance changes of this lake 
Ayakkum

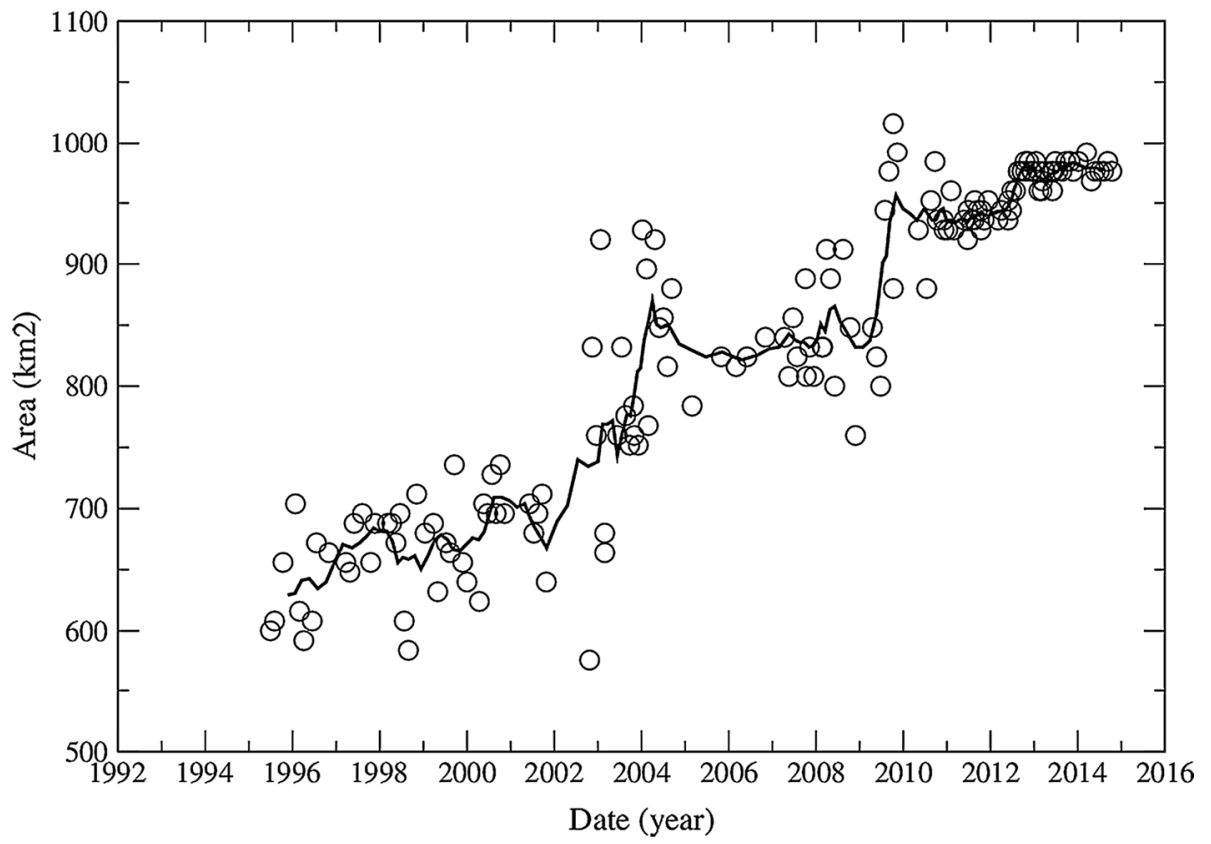

Fig. 10 Calculation of Lake Ayakkum areal extent from a combination of satellite altimetry and satellite imagery (using the hypsometry polynomial given in Fig. 9)

over the previous 50 years and have shown that it is controlled by snow and glacier melt and inter-annual precipitation variability (between 300 and $500 \mathrm{~mm} / \mathrm{year}$ ). They calculated that glacier melting increased the lake level by $17.5 \mathrm{~m}$ and the volume by $33.5 \mathrm{~km}^{3}$. They also compared and validated their model's results to altimetry data for the period 2005-2009. Liu et al. (2009b) used satellite imagery (Landsat and CBERS) to measure areal extent variations of this lake since 1976. They tried to link these changes to variations of E, P, and R. They revealed that the wetter and warmer winter climate since the late 1980's and mid-1990's has increased the ground temperature which has in turn enhanced spring surface runoff and glacier melting. Meanwhile, it has decreased the seasonal underground frost (from 2.35 to $1.93 \mathrm{~m}$ on average) leading to acceleration of the permafrost contribution to the lake's water balance. Liu et al. (2009b) also detected the years when abrupt changes were observed in different climate variables (E, P, R, air temperature) in the watershed of Lake Namco. Results from their analysis show that 1996 was a key year for runoff changes, with a $20 \%$ increase in annual discharge, leading the lake to expand.

In another study, Kropáček et al. (2012) processed the satellite altimetry data from Geosat Follow On (GFO), Envisat and ICESat, from 2000 to 2009, and satellite images from Landsat satellites over the period 1976-2009. They observed an expansion of the lake of $82 \mathrm{~km}^{2}$ (also confirmed in Zhang et al. (2011b)) and an increase in the water level of $0.31 \mathrm{~m} /$ year during the period of measurements. This coincides quite well with the results obtained by Krause et al. (2010), although they mentioned stabilization of the lake level after 2005.

Zhang et al. (2011b) estimated Lake Namco water storage changes and its link with climate change using different sources of information: meteorological data from 1976 to 2009, satellite images, and lake bathymetry. They estimated the total water storage 
Ayakkum

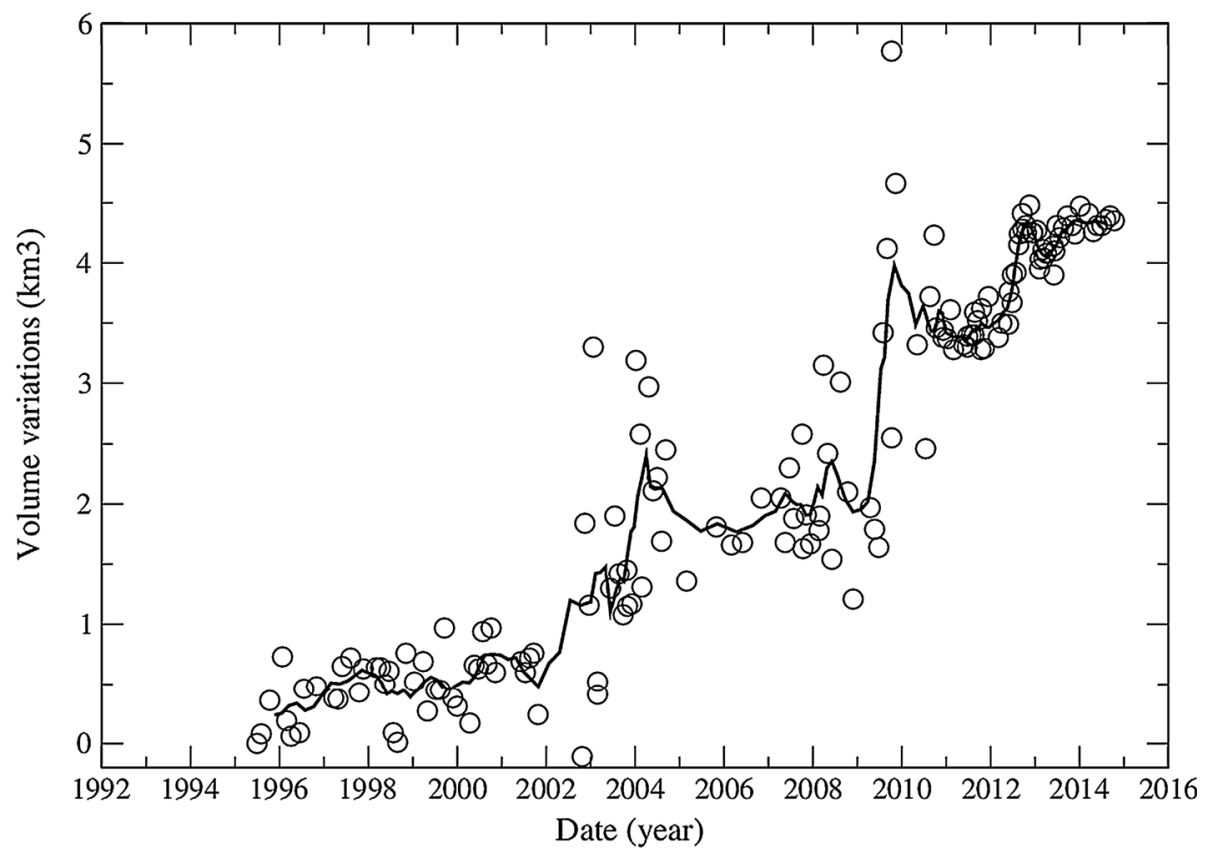

Fig. 11 Volume variations for Lake Ayakkum using variations of altitude and areal extent given in Figs. 8 and 10

increase over the period of study of $9 \mathrm{~km}^{3}$ and an area growth of $88 \mathrm{~km}^{2}$ in good agreement with work obtained by Kropáček et al. (2012). From Fig. 16, we can see that this exactly corresponds to the lake volume change inferred from altimetry and imagery from 1996 to 2005. They concluded that the main origin of lake growth is rising temperature which yields to increasing discharge from glacier thawing. Wu et al. (2014) have developed a model which tends to demonstrate that this lake is in constant expansion, and they validate their model using 2003-2009 ICESat data. However, they noted a diminishing rate of lake level rising at the end of the study period.

Figure 15a shows the water level variations of this lake inferred from 20 years of multisatellite altimetry missions (ERS2, Envisat, ICESat, Cryosat-2, and SARAL/AltiKa). We clearly see that it has increased relatively continuously from 1995 to 2005 and has now reached a stable level (until end of 2014) of about $4725 \mathrm{~m}$ a.s.l. Has the lake reached a new equilibrium surface? This would mean that with an equilibrium response time of 160 years, if recent evolution of this lake is due to climate warming and started around the year 1996 as shown in Liu et al. (2009b), then lake level stabilization around the years 2005-2006 is an indication that climate conditions have changed again: It could be due to deceleration of glaciers melting in the watershed of Lake Namco following a decade of acceleration. It could also be due to a large decrease in precipitation in the watershed. In either case, it must be confronted and assimilated into lake models. This unique example shows that recent research that tries to explain the expansion of Lake Namco in the light of glacier acceleration and permafrost melting should take into account this lake's new state. 


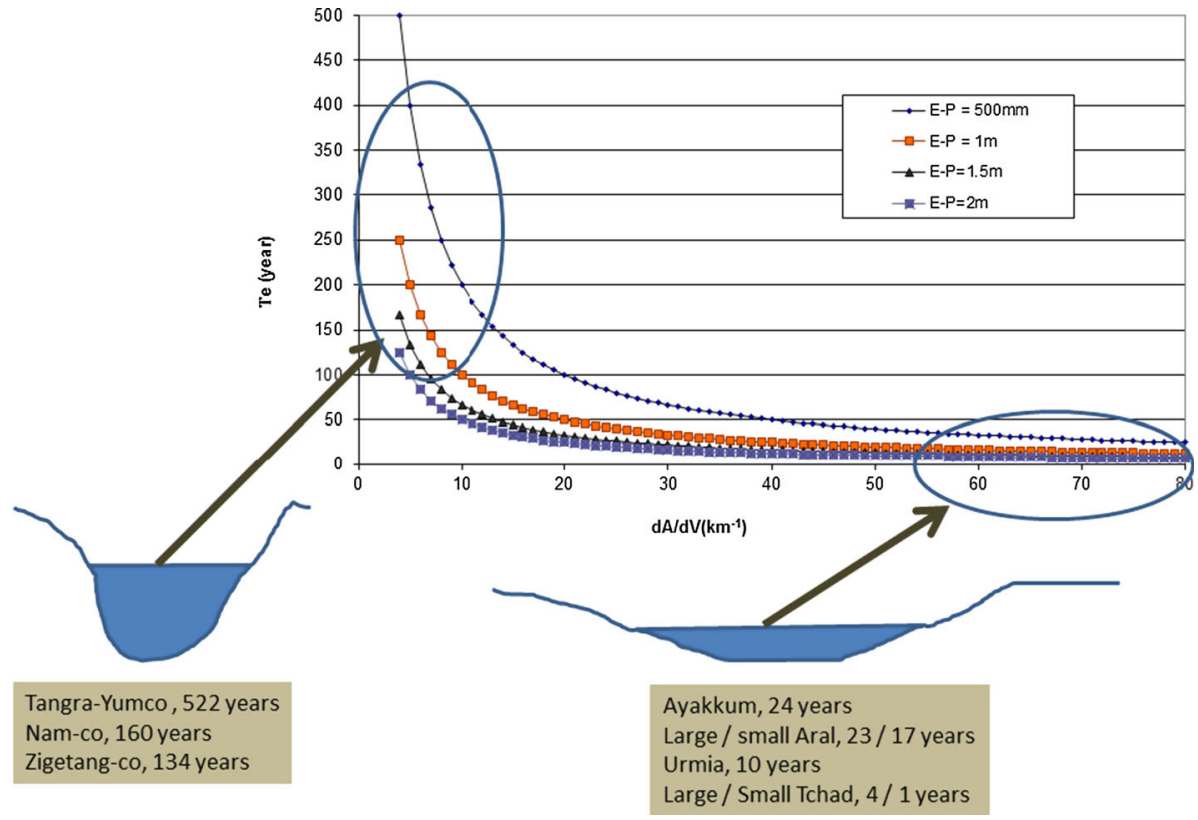

Fig. 12 Simulation of the equilibrium response time for lakes with various types of morphologies: from steep bathymetry to shallow lakes based on the equations given in Mason et al. (1994)

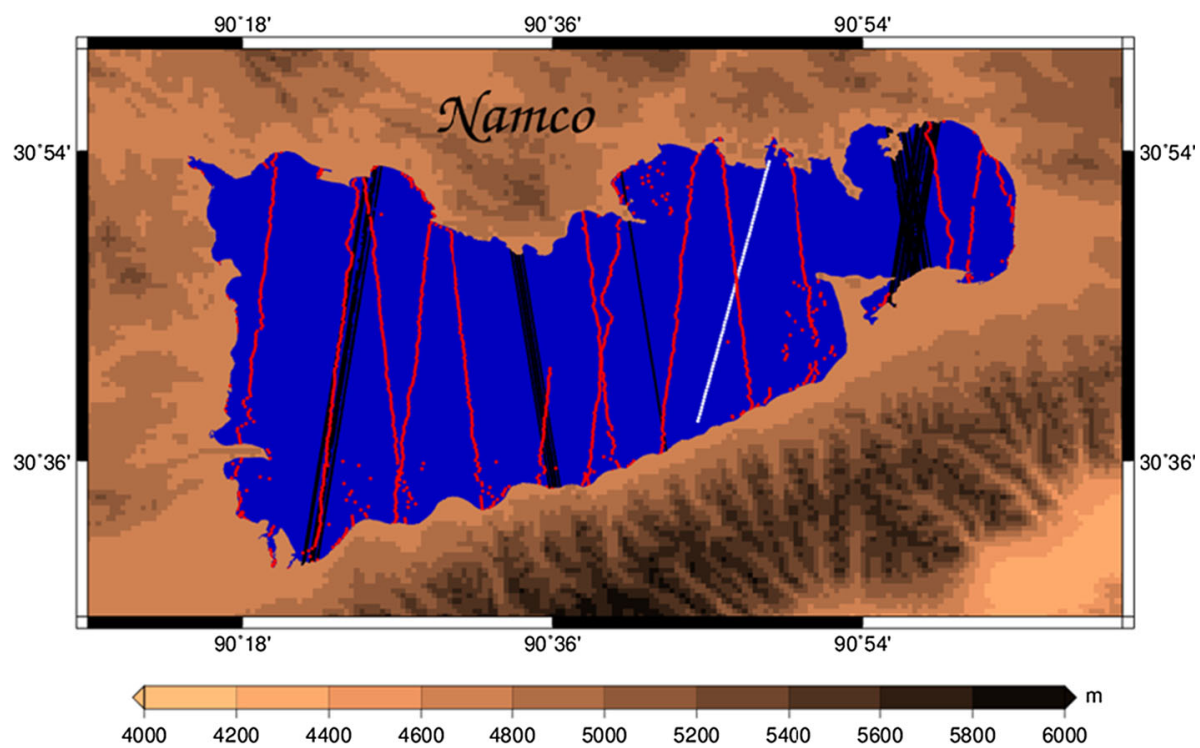

Fig. 13 Map of Lake Namco. White lines represent the ERS2, Envisat and SARAL/AltiKa tracks, red lines the Cryosat- 2 tracks and black lines the ICESat tracks 


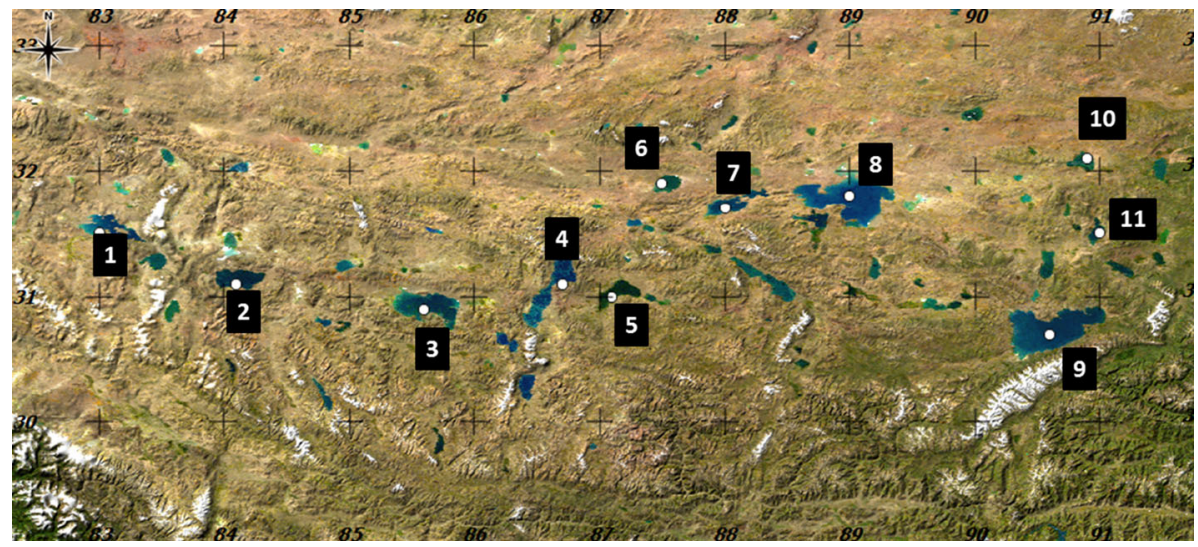

Fig. 14 Map of the 11 large lakes of the southern part of the TP. 1: Ngangla Ringco, 2: Taro Co, 3: Zhari Namco, 4: Tangra Yumco, 5: Ngangze, 6: Dagze Co, 7: Urru Co, 8: Ziling, 9: Namco, 10: Zigetangco, 11: Pung Co

We shall now look at a set of large lakes located in the southern part of the TP with longitudinal distribution around latitude $31^{\circ}-32^{\circ}$ North (Fig. 14). It includes the TP's two main lakes: Lake Ziling and Lake Namco. We chose only lakes with a minimum of 10 years of observation. In fact, the majority of them benefit from more than 20 years of multi-satellite data. What can be learnt from the water level time series of these lakes in terms of climate change? In another words, can the time series of these lakes be used to indicate and quantify climate change impact on the lakes of the TP?

Among these lakes, six of them clearly present a similar increase in their water level that started in 1997-1998: Ziling, Nganze, Zhari Namco, Dagze co, Zigetangco, and Tangra Yumco (Fig. 15c-g, k). The Dagze Co (Fig. 15f) and Zigetangco (Fig. 15d) continue to expand at the same high rate in 2014, while Ziling (Fig. 15e) and Ngangze (Fig. 15c) started to increase at a lower rate after 2006, and the Zhari Namco (Fig. 15k) started to shrink in 2009-2010. For the Zhari Namco (Fig. 15k), there is a clear oscillation at decadal timescale which can only be seen with 20 years' worth of data. For the four others, it is difficult to detect whether the trend observed after 1998 will continue or whether we can only observe a portion of longer time scale fluctuations. In contrast to this, Namco (Fig. 15a) and Pung Co (Fig. 15b), lake water levels that increased continuously until 2006 have now stabilized to a constant value. The water level of Lake Urru Co (Fig. 15h) seemed to stabilize earlier (in 2002). Taro Co (Fig. 15i) and Ngangla Ringco (Fig. 15j) started to shrink after 2010, significantly for the former, and slightly for the latter.

Lei et al. (2013a, b) analyzed the water storage and water balance variations of lakes Ziling, Namco, Pung Co and Zigetangco from 1976 to 2010 using a combination of satellite imagery and bathymetry of these lakes. Their results are in very good agreement with the water volume calculated in the Hydroweb database and reproduced in Fig. 16. However, time sampling of the water volume variations in Lei et al. (2013a, b) is rather irregular. This can be refined using satellite altimetry results which provide quite interesting results between 1994 and 2000 for these four lakes. It was mentioned above that lakes Namco and Pung Co (for example) grew at a reasonably steady rate from 1996 to 2005, while Lake Zigetangco started to grow around 1997-1998. The results for Lake 
(a)

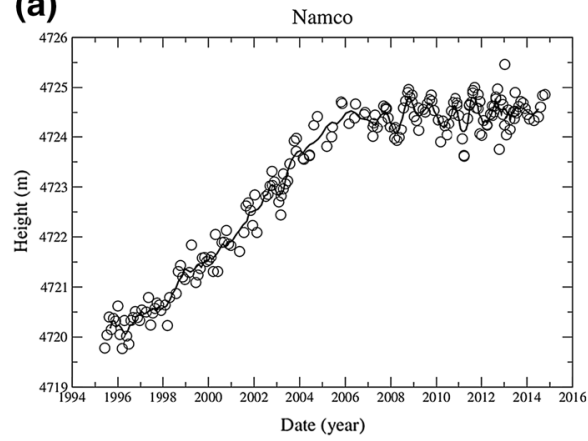

(c)

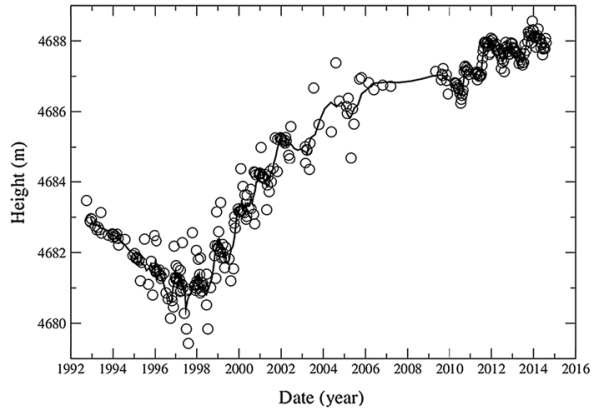

(e)

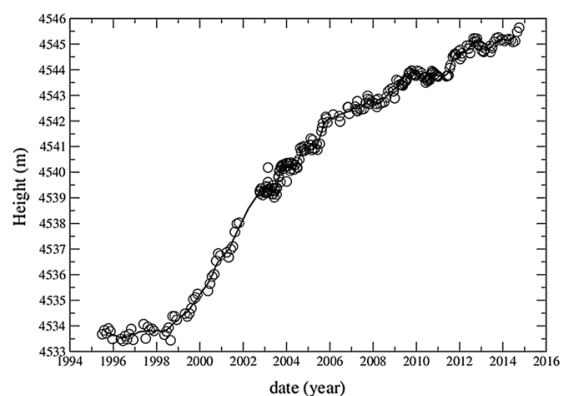

(g)

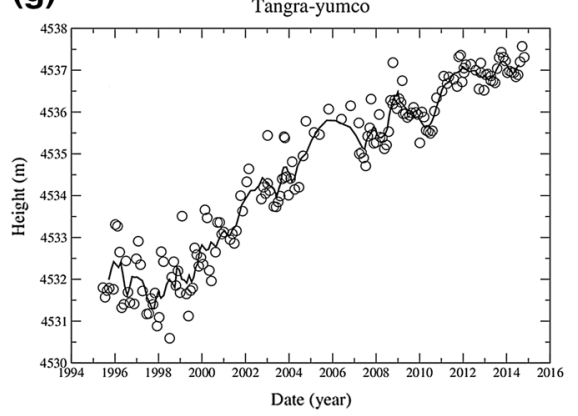

(b) Pung-co

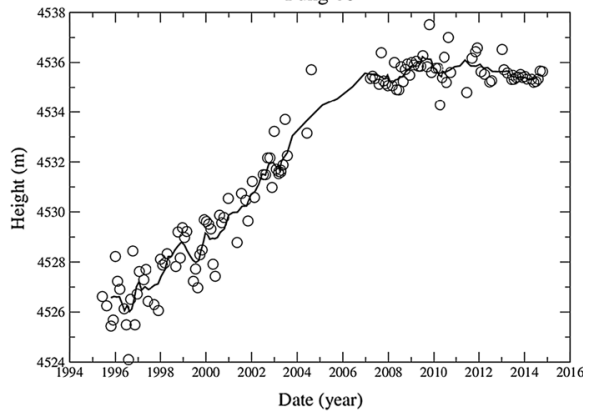

(d)

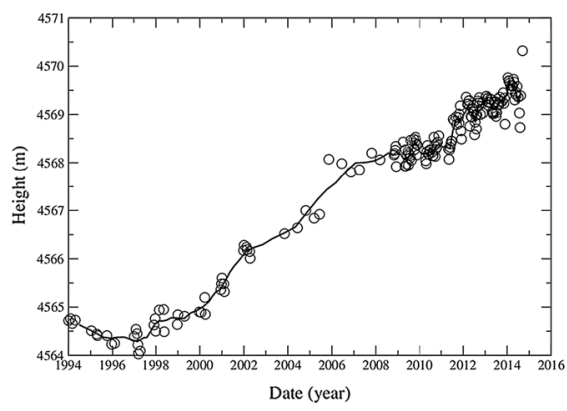

(f)

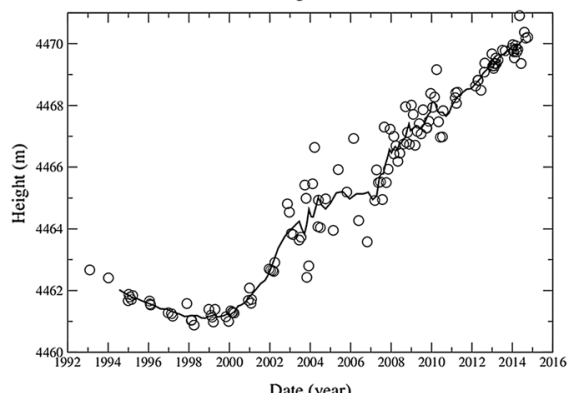

(h)

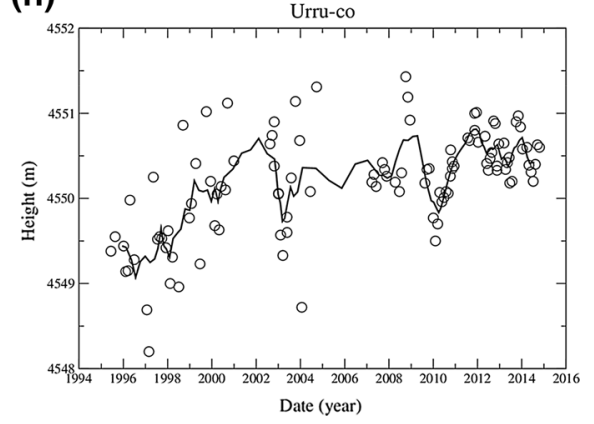

Fig. 15 Water height of 11 large lakes of the Tibetan Plateau from satellite altimetry 

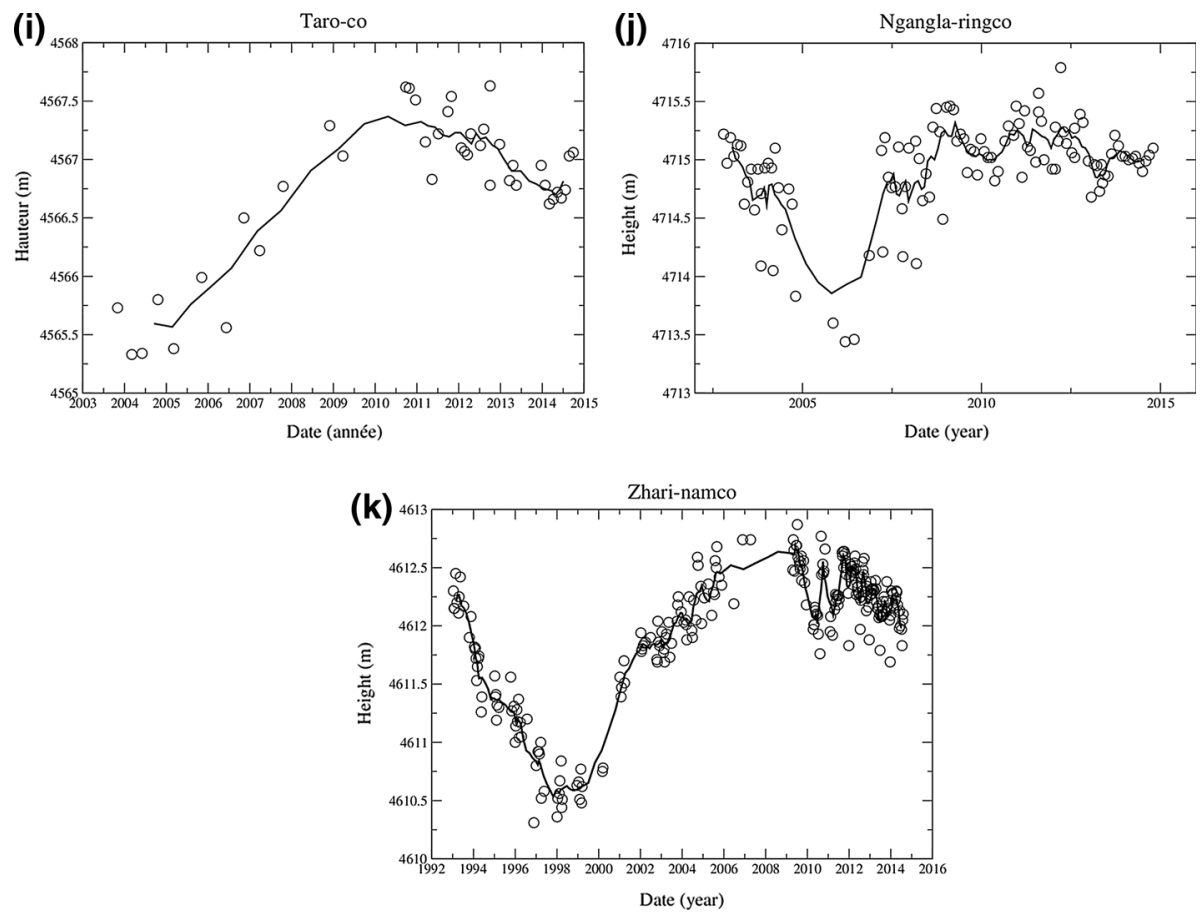

Fig. 15 continued

Ziling are in very good agreement with the results of Lei et al. (2013a, b). They also modeled the water balance from meteorological data and concluded that lake storage changes were due to an increase in precipitation and runoff and a decrease in evaporation. They also concluded that for Lake Namco the melting glaciers had a higher impact on lake storage change, which was less true for the other lakes. Unfortunately, their model was valid only until 2006 and did not allow them to detect the stabilization of lakes Namco and Pung Co after this date. Results of Liu et al. (2009b) were in better agreement with satellite altimetry for the period 1994-2000 as they clearly revealed an abrupt change in 1996 for Lake Namco. In Hwang et al. (2005) water level variations of Lake Ngangze were analyzed, and they concluded that this lake was under the influence of the South Indian Monsoon correlated with El Nino. Air moisture in the region has increased causing (in particular) the abrupt change of the lake level in 1998 (Fig. 15c). What can be observed using altimetry for lakes such as Lakes Ziling (Fig. 15e), Dagze Co (Fig. 15f), Ngangze (Fig. 15c) or Zhari Namco (Fig. 15k) is an abrupt change in water level from 1998 to 1999 that could be a result of the same phenomenon. However, in such cases, it does not explain why other lakes under the same climatic conditions (Tangra Yumco (Fig. 15g), Pung Co (Fig. 15b) or Namco (Fig. 15a)) present rather different behavior (changes that occurred 2-3 years earlier). Instead, we think that the differences observed between these lakes are more likely due to a conjunction of different causes: glaciers and permafrost melting, $\mathrm{P}$ and E changes, and long decadal climate fluctuations with inter-annual responses controlled by their morphology. 


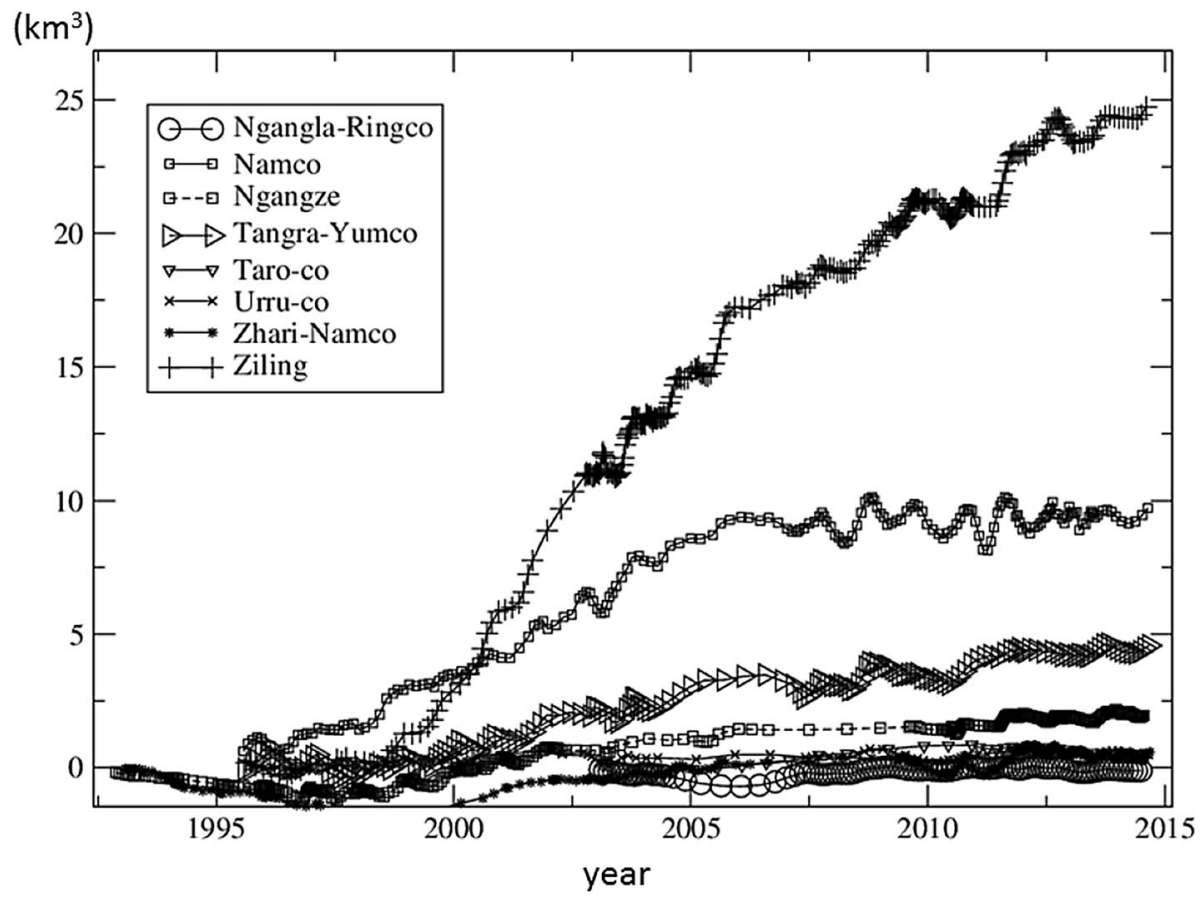

Fig. 16 Water volume changes for the 11 big lakes of South Tibet inferred from satellite altimetry combined with satellite imagery

The equations of the water budget of a lake, as defined by Mason et al. (1994) show that it is often necessary to observe water level and surface variations over decades in order to analyze the evolution of a lake. It is easy to discern (Fig. 15a-k) that although all of the large lakes of South Tibet [apart from Lake Ngangla Ringco (Fig. 15j)] grew in height and size very significantly between 2003 and 2009, at least half of them (Namco, Urru Co, Taro Co, Pung Co, Zhari Namco: Fig. 15a, b, h, i, k, respectively) reached apparent equilibrium or have even shrunk since the end of the year 2000. Many possibilities can be supposed: the lakes (Namco, Pung Co, Urru Co: Fig. 15a, b, h, respectively) have or have not yet (Ziling, Ngangze, Tangra Yumco, Zigetangco, Dagze Co: Fig. 15c, e, f, g, k respectively) reached a new equilibrium, or they follow a pluri annual cycle as seems to be the case for Lake Zhari Namco (Fig. 15k) or Lake Taro Co (Fig. 15i).

For all of these lakes, we have also calculated area and volume variations. We can see that the main part of total volume changes for the 11 lakes chosen here results from three lakes: Lake Ziling with $25 \mathrm{~km}^{3}$ during the 20 years of measurements, Lake Namco with $9 \mathrm{~km}^{3}$ between 1996 and 2005 and Lake Tangra Yumco with $5 \mathrm{~km}^{3}$ over the last 20 years. For the other lakes the contribution is much lower (Fig. 16).

\section{Conclusions}

Analyzing the causes of water height variations of lakes and understanding the processes involved in their water level and storage variations depends on the availability of observations over long periods of time. In many regions, the network of ground gauges is absent 
or too limited. This requires maintaining a constellation of satellites with continuity, overlap, and service over decades. However, the main reason the space agencies have been driven to continue developing altimetry missions in the future is principally due to the operational and research applications for oceanography. Within the past 20 years the use of satellite altimetry for hydrology has emerged and influenced future missions by employing new instrumental concepts (SAR, SARin, Ka band Altimetry, Ka interferometry) which are more suitable for continental waters.

Methodologies for calculating water level and volume variations using satellite data are not straightforward and require the development of specific approaches in order to correct the measurements for some effects like geoid slope errors. Satellite imagery processing also leads to algorithm development to extract the water contour of lakes that are mostly based on normalized indexes. The Hydroweb database provides the water level for about 230 lakes worldwide to scientists who do not want to process the altimetry data themselves. For some specific regions or individual lakes, the Hydroweb also produces areal extent and volume variations of lakes, as is done for many lakes over the Tibetan Plateau. The accuracy of satellite altimetry can be calculated using in situ measurements as ground truth. It generally ranges from a few centimeters for large lakes to a few decimeters for narrow reservoirs or rivers. However, it is often the only tool to measure water level and to analyze the impact of climate variability over continental waters. Many missions have been launched since 1992 with T/P, SARAL/AltiKa, Cryosat-2 and Jason-2 still in orbit, while Jason-3 has just been launched and Sentinel-3 will soon be launched. Methods to combine the products of each of these missions with past ones like ERS2, Envisat, GFO, T/P or Jason-1 can be developed in order to produce decadal water level time series.

Satellite altimetry and satellite imagery together are now widely used for the calculation of lake and reservoir water storage changes worldwide in order to study their inter-annual variability. By using the lakes over the TP we have illustrated some key aspects and issues (technical and scientific) linked with the survey of climate change impacts on surface waters from remote sensing data.

- The lakes respond to climate change (cyclic and secular) occurring at regional to global scale.

- They present a high variety of behavior depending on climate conditions and on their morphology.

- In contrast to general observations for rivers, the temporal variability of lake water height is dominated by large temporal scales as seen in the Tibetan Plateau.

We have seen that for the big lakes over the Central TP the water levels respond to climate change and may vary a lot from one lake to another. Many authors have measured water level variations of Tibetan lakes using short periods of altimetry measurements and tried to analyze their results within the framework of climate change using model or some climate variables. The link with glaciers and permafrost melt or precipitation changes are likely to be the origin of many of the observed changes, but the time series used are certainly too short to lead to definitive conclusions, and processes beyond observation are still uncertain. For example, in 2005 and 2006 lakes Namco and Pung Co reached an equilibrium value which was not the case for other lakes in the vicinity like lakes Ziling or Tangra Yumco. Other lakes like the Zhari Namco or Taro Co seem to be dominated by cyclic variations. The influence of a lake's morphology enters into the calculation of the time response for a lake to reach a new state of equilibrium, and is a key aspect often neglected in the current literature. 
Acknowledgments The authors acknowledge the Centre National d'Etudes Spatiales (CNES) for financing our project through the TOSCA project. The authors are also grateful to the Centre for Topographic Studies of the Oceans and Hydrosphere (CTOH, www.legos.obs-mip.fr/observations/ctoh) at LEGOS (Toulouse, France) for providing altimetry data in a standard and useful form. The Landsat data have been downloaded from the Earth explorer system of United States Geological Survey (USGS) from their web site: http://earthexplorer.usgs.gov/. We are grateful for this service.

Open Access This article is distributed under the terms of the Creative Commons Attribution 4.0 International License (http://creativecommons.org/licenses/by/4.0/), which permits unrestricted use, distribution, and reproduction in any medium, provided you give appropriate credit to the original author(s) and the source, provide a link to the Creative Commons license, and indicate if changes were made.

\section{References}

Abarca-del-Rio R, Crétaux J-F, Berge-Nguyen M, Maisongrande P (2012) Does the Titicaca Lake still control the Poopo lake water levels? An investigation using satellite altimetry, and MODIS data (2000-2009). Remote Sens Lett 3(8):707-714

Abileah R, Vignudelli S, Scozzari A (2011) A completely remote sensing approach to monitoring reservoirs water volume. Int Water Technol J 1:63-77

Adrian R, O'Reilly CM, Zagarese H et al (2009) Lakes as sentinels of climate change. Limnol Oceanogr 54(6):2283-2297

Aladin NV, Crétaux J-F, Plotnikov IS, Kouraev AV, Smurov AO, Cazenave A, Egorov AN, Papa F (2005) Modern hydro-biological state of the Small Aral Sea. Environmetrics 16:1-18. doi:10.1002/env.709

Alsdorf DE, Birkett CM, Dunne T, Melack J, Hess L (2001) Water level changes in a large Amazon lake measured with spaceborne radar interferometry and altimetry. Geophys Res Lett 28(14):2671-2674

Altmann G, Rowland JC, Wilson CJ, Verbyla D, Charsley-Groffman L (2010) Quantification of inter-annual and inter-seasonal variability of lake areas within discontinuous permafrost of the Yukon Flats, Alaska. Abstract H41B-1090 presented at 2010 Fall Meeting, AGU, San Francisco, California, 13-17 December

Arsen A, Crétaux J-F, Berge-Nguyen M, Abarca del Rio R (2014) Remote sensing derived bathymetry of Lake Poopó. Remote Sens 6(1):407-420

Arsen A, Cretaux J-F, Abarca Del Rio R (2015) Use of SARAL/AltiKa over mountainous lakes, intercomparison with Envisat mission. Mar Geodes 38(1):534-548. doi:10.1080/01490419.2014.1002590

Aus Der Beck T, Voss F, Flörke M (2011) Modelling the impact of global change on the hydrological system of the Aral Sea basin. Phys Chem Earth 36(13):684-695. doi:10.1016/j.pce.2011.03.004

Baghdadi N, Lemarquand N, Abdallah H, Bailly JS (2011) The relevance of GLAS/ICESat elevation data for the monitoring of river networks. Remote Sens 3:708-720

Balsamo G, Saigao R, Dutra E, Boussetta S, Stockdale T, Potes M (2012) On the contribution of lakes in predicting near-surface temperature in a global weather forecasting model. Tellus Ser A Meteorol Oceanogr 9:15829. doi:10.3402/tellusa.v64i0.15829

Bates PD, Neal JC, Alsdorf D, Schumann GJP (2014) Observing global surface water flood dynamics. Surv Geophys 35(3):839-852

Berry PAM, Garlick JD, Freeman JA, Mathers EL (2005) Global inland water monitoring from multimission altimetry. Geophys Res Lett 32:L16401. doi:10.1029/2005GL022814

Biancamaria S, Andreadis KM, Durand M, Clark EA, Rodriguez E, Mognard NM, Alsdorf DE, Lettenmaier DP, Oudin Y (2010) Preliminary characterization of SWOT hydrology error budget and global capabilities. IEEE J Special Issue Microw Remote Sens Land Hydrol Res Appl 3(1):6-19. doi:10.1109/ JSTARS.2009.2034614

Birkett CM (1995) Contribution of TOPEX/POSEIDON to the global monitoring of climatically sensitive lakes. J Geophys Res 100(C12):25179-25204

Birkett CM (1998) Contribution of the Topex NASA radar altimeter to the global monitoring of large rivers and wetlands. Water Resour Res 34(5):1223-1239

Birkett CM, Beckley B (2010) Investigating the Performance of the JASON-2/OSTM Radar Altimeter over Lakes and Reservoirs. Mar Geodesy 33(1):204-238

Birkett CM, Murtugudde R, Allan T (1999) Indian Ocean climate event brings floods to East Africa's lakes and the Sudd Marsh. Geophys Res Lett 26:1031-1034

Bliss A, Hock R, Radić V (2014) Global response of glacier runoff to twenty-first century climate change. J Geophys Res Earth Surf 119(4):717-730 
Bonnefond P, Exertier P, Laurain O et al (2010) Absolute calibration of Jason-1 and JASON-2Altimeters in Corsica during the formation flight phase. Mar Geod 33(S1):80-90

Boschetti M, Nutini F, Manfron G, Brivio PA, Nelson A (2014) Comparative analysis of normalised difference spectral indices derived from MODIS for detecting surface water in flooded rice cropping systems. PLoS ONE 9(2):e88741. doi:10.1371/journal.pone.0088741

Bowling LC, Lettenmaier DP (2010) Modeling the effects of lakes and wetlands on the water balance of Arctic environments. J Hydrometeorol 11(2):276-295. doi:10.1175/2009JHM1084.1

Brenner AC, Bentley CR, Csatho BM, Harding DJ, Hofton MA, Minster J, Roberts L, Saba JL, Schutz R, Thomas RH, Yi D, Zwally HJ (2000) Derivation of range and range distributions from laser pulse waveform analysis for surface elevations, roughness, slope, and vegetation heights. Algorithm theoretical basis document. Version 3.0. Greenbelt, MD, USA

Brown GS (1977) The average impulse response of a rough surface and its applications. IEEE Trans Antennas Propag 25:67-74. doi:10.1109/TAP.1977.1141536

Calmant S, Seyler F, Cretaux J-F (2008) Monitoring continental surface waters by satellite altimetry. Surv Geophys 29(4-5):247-269. doi:10.1007/s10712-008-9051-1

Chavez PS Jr (1989) Radiometric calibration of landsat thematic mapper multispectral images. Photogramm Eng Remote Sens 55:1285-1294

Chavez PS Jr (1996) Image-based atmospheric corrections-revisited and improved. Photogramm Eng Remote Sens 62:1025-1036

Cheng K-C, Kuo C-Y, Tseng H-Z et al (2010) Lake surface height Calibration of Jason-1 and Jason-2 over the Great Lakes. Mar Geod 33(S1):186-203

Coe MT, Birkett CM (2005) Water resources in the Lake Chad basin: prediction of river discharge and lake height from satellite radar altimetry. Water Resour Res. doi:10.1029/2003WR002543

Crétaux J-F, Birkett CM (2006) lake studies from satellite altimetry. C R Geosci. doi:10.1016/J.crte.2006. 08.002

Cretaux J-F, Jelinski W, Calmant S, Kouraev AV, Vuglinski VV, Bergé Nguyen M, Gennero M-C, Nino F, Abarca-Del-Rio R, Cazenave A, Maisongrande P (2011) SOLS: a lake database to monitor in Near Real Time water level and storage variations from remote sensing data. J Adv Space Res 47(9):1497-1507. doi:10.1016/j.asr.2011.01.004

Cretaux J-F, Letolle R, Bergé-Nguyen M (2013) History of Aral Sea level variability and current scientific debates. Glob Planet Changes 11:99-113

Cretaux J-F, Biancamaria S, Arsen A, Bergé-Nguyen M, Becker M (2015) Global surveys of reservoirs and lakes from satellites and regional application to the Syrdarya river basin. Environ Res Lett 10(1):015002. doi:10.1088/1748-9326/10/1/015002

Crétaux J-F, Kouraev AV, Papa F, Bergé Nguyen M, Cazenave A, Aladin NV, Plotnikov IS (2005) Water balance of the Big Aral sea from satellite remote sensing and in situ observations. J Great Lakes Res 31(4):520-534

Crétaux J-F, Calmant S, Romanovski V, Perosanz F, Tashbaeva S, Bonnefond P, Moreira D, Shum CK, Nino F, Bergé-Nguyen M, Fleury S, Gegout P, Abarca Del Rio R, Maisongrande P (2011) Absolute calibration of Jason radar altimeters from GPS kinematic campaigns over Lake Issykkul. Mar Geod 34(3-4):291-318. doi:10.1080/01490419.2011.585110

Crétaux J-F, Bergé-Nguyen M, Calmant S, Romanovski VV, Meyssignac B, Perosanz F, Tashbaeva S, Arsen A, Fund F, Martignago N, Bonnefond P, Laurain O, Morrow R, Maisongrande P (2013) Calibration of Envisat radar altimeter over Lake Issykkul. J Adv Space Res 51(8):1523-1541. doi:10.1016/ j.asr.2012.06.039

De Wit M, Stankiewicz J (2006) Changes in surface water supply across Africa with predicted climate change. Science 311(5769):1917-1921

Downing JA (2010) Emerging global role of small lakes and ponds: little things mean a lot. Limnetica 29(1):9-24

Downing JA, Prairie YT, Cole JJ, Duarte CM, Tranvik LJ, Striegl RG, McDowell WH, Kortelainen P, Caraco NF, Melack JM, Middelburg J (2006) The global abundance and size distribution of lakes, ponds, and impoundments. Limnol Oceanogr 51:2388-2397. doi:10.4319/lo.2006.51.5.2388

Duan Z, Bastiaanssen WGM (2013) Estimating water volume variations in lakes and reservoirs from four operational satellite altimetry databases and satellite imagery data. Remote Sens Environ 134:403-416

Dudgeon D, Arthington AH, Gessner MO, Kawabata Z-I, Knowler DJ, Lévêque C, Naiman RJ, PrieurRichard A-H, Soto D, Stiassny MLJ, Sullivan CA (2006) Freshwater biodiversity: importance, threats, status and conservation challenges. Biol Rev 81:163-182. doi:10.1017/S1464793105006950

Eriksson M, Jianshu X, Shrestha AB, Vaidya RA, Nepal S, Sandstrom K (2009) The changing Himalayas: impact of climate change on water resources and livelihoods in the greater Himalayas. ICIMOD, Kathmandu 
Frappart F, Calmant S, Cauhopé M, Seyler F, Cazenave A (2006) Results of ENVISAT RA-2 derived levels, validation over the Amazon basin. Remote Sens Environ 100:252-264

Gao H, Birkett CM, Lettenmeir DP (2012) Global monitoring of large reservoir storage from satellite remote sensing. Water Resour Res 48:W09504. doi:10.1029/2012WR012063

Gao T, Kang S, Cuo L, Zhang T, Zhang G, Zhang Y, Sillanpaa M (2015) Simulation and analysis of glacier runoff and mass balance in the Nam Co basin, southern Tibetan Plateau. J Glaciol 61(227):447

Halbfass W (1914) Das S̈usswasser der Erde (The freshwater of the Earth). Druch und Verlag von Philipp Reclam jun, Leipzig, p 189

Huang L, Liu J, Shao Q, Liu R (2011) Changing inland lakes responding to climate warming in northern Tibetan Plateau. Clim Change 24:479-502. doi:10.1007/s10584-011-0032-x

Hwang C, Peng M-F, Ning J, Luo J, Sui C-H (2005) Lake level variations in China from TOPEX/Poseidon altimetry: data quality assessment and links to precipitation and ENSO. Geophys J Int 161:1-11

Jarihani AA, Callow JN, Johansen K, Gouweleeuw B (2013) Evaluation of multiple satellite altimetry data for studying inland water bodies and river floods. J Hydrol 505: 78-90. ISSN 0022-1694. Doi:10.1016/ j.jhydrol.2013.09.010

Ji L, Zhang L, Wylie B (2009) Analysis of dynamic thresholds for the normalized difference water index. Photogramm Eng Remote Sens 75:1307-1317

Kang S, Xu Y, You Q, Flügel W, Pepin N, Yao T (2010) Review of climate and cryospheric change in the Tibetan Plateau. Environ Res Lett 5:8. doi:10.1088/1748-9326/5/1/015101

Kleinherenbrink M, Ditmar PG, Lindenbergh RC (2014) Retracking Cryosat data in the SARIn mode and robust lake level extraction. Remote Sens Environ 152:38-50

Kleinherenbrink M, Lindenbergh RC, Ditmar PG (2015) Monitoring of lake level changes on the Tibetan Plateau and Tian Shan by retracking Cryosat SARIn waveforms. J Hydrol 521:119-131

Koblinsky CJ, Clarke RT, Brenner AC, Frey H (1993) Measurement of river level variations with satellite altimetry. Water Resour Res 29(6):1839-1848. doi:10.1029/93WR00542

Kouraev AV, Semovski SV, Shimaraev MN, Mognard NM, Legresy B, Remy F (2007) Ice regime of lake Baikal from historical and satellite data: influence of thermal and dynamic factors. Limnol Oceanogr 52(3): $1268-1286$

Krause P, Biskop S, Helmschrot J, Flügel W-A, Kang S, Gao T (2010) Hydrological system analysis and modeling of tha Nam-Co basin in Tibet. Adv. Geosci 27:29-36. doi:10.5194/adgeo-27-29-2010

Kropáček J, Braun A, Kang S, Feng C, Ye Q, Hochschild V (2012) Analysis of lake level changes in Nam Co in central Tibet utilizing synergistic satellite altimetry and optical imagery. Int J Appl Earth Obs Geoinf 17:3-11. doi:10.1016/j.jag.2011.10.001

Laxon S (1994) Sea ice altimeter processing scheme at the EODC. Int J Remote Sens 15(4):915-924

Lee H, Durand M, Jung HC, Alsdorf D, Shum CK, Sheng T (2010) Characterization of surface water storage changes in Arctic lakes using simulated SWOT measurements. Int J Remote Sens 31(14):3931-3953. doi:10.1080/01431161.2010.483494

Lee H, Shum C-K, Tseng K-H, Guo J-Y, Kuo C-Y (2011) Present day lake level variation from Envisat altimetry over the North eastern Qinghai-Tibetan plateau: links with precipitation and temperature. Terr Atmos Ocean Sci 22(2):169-175. doi:10.3319/TAO.2010.08.09.01(TibXS)

Legresy B, Remy F (1997) Surface characteristics of the Antartic ice sheet and altimetric observations. J Glaciol 43(144):197-206

Lehner B, Döll P (2004) Development and validation of a global database of lakes, reservoirs and wetlands. J Hydrol 296:1-22. doi:10.1016/j.jhydrol.2004.03.028

Lei Y, Yao T, Bird BW, Yang K, Zhai J, Sheng Y (2013a) Coherent lake growth on the central Tibetan Plateau since the 1970s: characterization and attribution. J Hydrol 483:61-67

Lei Y, Yao T, Bird BW, Yang K, Zhai J, Sheng Y (2013b) Coherent lake growth on the central Tibetan Plateau since the 1970s: characterization and attribution. J Hydrol 483:61-67

Lei Y, Yang K, Wang B, Sheng Y, Bird BW, Zhang G, Tian L (2014) Response of inland lake dynamics over the Tibetan Plateau to climate change. Clim Change 125(2):281-290. doi:10.1007/s10584-014$1175-3$

Li XY, Xu HY, Sun YL, Zhang DS, Yang ZP (2007) Lake-level change and water balance analysis at Lake Qinghai, West China during recent decades. Water Resour Manag 21:1505-1516. doi:10.1007/s11269006-9096-1

Li X, Cheng G, Jin H, Kang E, Che T, Jin R, Wu L, Nan Z, Wang J, Shen Y (2008) Cryosphere change in China. Glob Planet Change 62:210-218

Li S, Zhan H, Lai Y, Sun Z, Pei W (2014) The coupled moisture-heat process of permafrost around a thermokarst pond in Qinghai-Tibet Plateau under global warming. J Geophys Res Earth Surf 119(4):836-853 
Liao J, Shen G, Li Y (2013) Lake variations in response to climate change in the Tibetan Plateau in the past 40 years. Int J Digit Earth 6(6):534-549

Liu XD, Chen BD (2000) Climatic warming in the Tibetan Plateau during recent decades. Int J Climatol 20(14):1729-1742

Liu J, Wang S, Yu S, Yang D, Zhang L (2009a) Climate warming and growth of high-elevation inland lakes on the Tibetan Plateau. Global Planet Change 67:209-217

Liu J, Kang S, Gong T, Lu A (2009b) Growth of a high-elevation large inland lake, associated with climate change and permafrost degradation in Tibet. Hydrol Earth Syst Sci Discuss 6:5445-5469

Liu J, Wang Z, Gong T, Uygen T (2012) Comparative analysis of hydroclimatic changes in glacier-fed rivers in the Tibet and Bhutan-Himalayas. Quat Int 282:104-112

López-Moreno JI, Fontaneda S, Bazo J et al (2014) Recent glacier retreat and climate trends in Cordillera Huaytapallana, Peru. Glob Planet Change 112:1-11

Ma R, Duan H, Hu C, Feng X, Li A, Ju W, Jiang J, Yang G (2010) A half-century of changes in China's lakes: global warming or human influence? Geophys Res Lett 37:L24106. doi:10.1029/2010GL045514

Mason IM, Guzkowska MAJ, Rapley CG, Street-Perrot FA (1994) The response of lake levels and areas to climate change. Clim Change 27:161-197

McDonald CP, Rover JA, Stets EG, Striegl RG (2012) The regional abundance and size distribution of lakes and reservoirs in the United States and implications for estimates of the global lake extent. Limnol Oceanogr 57:597-606. doi:10.4319/lo.2012.57.2.0597

McFeeters SK (1996) The use of Normalized Difference Water Index (NDWI) in the delineation of open water features. Int J Remote Sens 17(7):1425-1432

Medina C, Gomez-Enri J, Alonso J, Villares P (2008) Water level fluctuations derived from Envisat Radar altimetry (RA-2) and in situ measurements in a subtropical water body: lake Izabal (Guatemala). RSE. doi:10.1016/J.rse.2008.05.001

Mertikas SP, Ioannides RT, Tziavos IN et al (2010) Statistical models and latest results in the determination of the absolute bias for the radar altimeters of Jason satellites using the Gavdos facility. Mar Geod 33(S1):114-149

Meybeck M (1995) Global distribution of lakes. In: Lerman A, Imboden DM, Gat JR (eds) Physics and chemistry of lakes. Springer, Berlin, pp 1-36

Morris CS, Gill SK (1994) Evaluation of the Topex/Poseidon altimeter system over the great Lakes. J Geophys Res 99(C12):24527-24539

Neckel N, Kropáček J, Bolch T, Hochschil V (2014) Glacier mass changes on the Tibetan Plateau 2003-2009 derived from ICESat laser altimetry measurements. Environ Res Lett 9(1):014009

Nicholson SE, Yin X (2002) Mesoscale patterns of rainfall, cloudiness and evaporation over the Great lakes of East Africa, Kluwer Academic Publishers, The East African great lakes: limnology, paleolimnology and biodiversity, Advance in global change research, vol 12

Otsu N (1979) A threshold selection method from gray-level histograms. IEEE Syst Man Cybern 9(1):62-66

Ouma YO, Tateishi R (2006) A water index for rapid mapping of shoreline changes of five East African Rift Valley lakes: an empirical analysis using Landsat TM and ETM data. Int J Remote Sens 27(15):3153-3181

Pandey RK, Crétaux J-F, Bergé-Nguyen M, Mani Tiwari V, Drolon V, Papa F, Calmant S (2014) Water level estimation by remote sensing for 2008 flooding of the Kosi river. Int J Remote Sens 35(2):424-440. doi:10.1080/01431161.2013.870678

Phan VH, Lindenbergh R, Menenti M (2011) ICESat derived elevation changes of Tibetan lakes between 2003 and 2009. Int J Appl Earth Observ Geoinf. doi:10.1016/j.jag.2011.09.015

Phan VH, Lindenbergh RC, Menenti M (2013) Geometric dependency of Tibetan lakes on glacial runoff. Hydrol Earth Syst Sci Discuss 10:729-768. doi:10.5194/hessd-10-729-2013

Rast W, Straskraba M (2000) Lakes and reservoirs, similarities, differences and importance. Short series on planning and management of lakes and reservoirs, UNEP-IETC (International Environment Technological Center)/ILEC (International Lake Environment Committee Foundation), vol 1, 24 p, ISBN: 4-906356-27-3 (available at http://www.ilec.or.jp/en/pubs/p2/lake-resvr)

Raymond PA, Hartmann J, Lauerwald R et al (2013) Global carbon dioxide emissions from inland waters. Nature 503(7476):355-359

Ričko M, Birkett CM, Carton JA, Cretaux J-F (2012) Intercomparison and validation of continental water level products derived from satellite radar altimetry. J Appl Remote Sens 6:061710. doi:10.1117/1. JRS.6.061710

Robertson DM, Ragotzkie RA (1990) Changes in the thermal structure of moderate to large sized lakes in response to changes in air temperature. Aquat Sci 52(4):360-380

Rodriguez E (2015) Surface Water and Ocean Topography project, science requirement document, release February 2015, JPL D-61923 
Sakamoto T, Nguyen NV, Kotera A, Ohno H, Ishitsuka N, Yokozawa M (2007) Detecting temporal changes in the extent of annual flooding within the Cambodia and the Vietnamese Mekong Delta from MODIS time-series imagery. Remote Sens Environ 109(3):295-313

Schindler DW (2009) Lakes as sentinels and integrators for the effects of climate change on watersheds, airsheds, and landscapes. Limnol Oceanogr 54(6):2349-2358

Schwatke C, Dettmering D, Bosch W, Seitz F (2015) Kalman filter approach for estimating water level time series over inland waters using multi-mission satellite altimetry. HESS Discuss 12:4813-4855. doi:10. 5194/hessd-12-4813-2015

Seekell DA, Carr JA, Gudasz C, Karlsson J (2014) Upscaling carbon dioxide emissions from lakes. Geophys Res Lett 41(21):7555

Silva JS, Calmant S, Seyler F, Moreira DM, Oliveira D, Monteiro A (2014) Radar altimetry aids managing gauge networks. Water Resour Manag 28-3:587-603. doi:10.1007/s11269-013-0484-z

Sima S, Tajrishy M (2013) Using satellite data to extract volume-area elevation relationships for Urmia Lake, Iran. J Great Lakes Res 39(1):90-99. doi:10.1016/j.jglr.2012.2.013

Singh A, Seitz F, Schwatke C (2012) Inter-annual water storage changes in the Aral Sea from multi-mission satellite altimetry, optical remote sensing, and GRACE satellite gravimetry. Remote Sens Environ 123:187-195

Solomon S, Qin D, Manning M, Chen Z, Marquis M, Averyt K, Tignor M, Miller H (eds) (2007) The physical science basis. In: Contribution of working group I to the fourth assessment report of the intergovernmental panel on climate change, IPCC. Cambridge University Press: Cambridge

Song X, Huang C, Sexton JO, Feng M, Narasimhan R, Channan S, Townshend JR (2011) An assessment of global forest cover maps using regional higher-resolution reference datasets. In: Proceedings of IEEE international geoscience and remote sensing symposium, 752-755

Song C, Huang B, Ke L (2013) Modeling and analysis of lake water storage changes on the Tibetan Plateau using multi-mission satellite data. Remote Sens Environ 135:25-35

Song C, Huang B, Ke L, Richards KS (2014a) Seasonal and abrupt changes in the water level of closed lakes on the Tibetan Plateau and implications for climate impacts. J Hydrol 514:131-144

Song C, Huang B, Ke L (2014b) Inter-annual changes of alpine inland lake water storage on the Tibetan Plateau: detection and analysis by integrating satellite altimetry and optical imagery. Hydrol Process 28(4):2411-2418

Song C, Huang B, Richards K, Ke L, Hien Phan V (2014c) Accelerated lake expansion on the Tibetan Plateau in the 2000s: induced by glacial melting or other processes? Water Resour Res 50(4):3170-3186

Song C, Ye Q, Cheng X (2015) Shifts in water-level variation of Namco in the central Tibetan Plateau from ICESat and CryoSat-2 altimetry and station observations. Sci Bull 60(14):1287-1297

Street-Perrott FA, Guzkowska MAJ, Mason IM, Rapley CG (1986) Response of lake levels to climatic change-past, present and future. In: Titus JG (ed) Effects of changes in stratospheric ozone and global climate, vol. 3 Climate Change, Proceedings of the United Nations/Environmental Protection Agency International Conference on Health and Environmental Effects of Ozone Modification and Climate Change, Washington DC, USA, 16-20 June 1986, EPA/UNEP, 211-216

Tarpanelli A, Brocca L, Barbetta S, Faruolo M et al (2015) Coupling MODIS and radar altimetry data for discharge estimation in poorly gauged river basins. IEEE Trans Geosci Remote Sens 8(1):141-148. doi:10.1109/JSTARS.2014.2320582

Tierney JE, Smerdon JE, Anchukaitis KJ, Seager R (2013) Multidecadal variability in East African hydroclimate controlled by the Indian Ocean. Nature 493(7432):389-392

Tranvik LJ, Downing JA, Cotner JB et al (2009) Lakes and reservoirs as regulators of carbon cycling and climate. Limnol Oceanogr 54(6part2):2298-2314

Verpoorter C, Kutser T, Seekell DA, Tranvik LJ (2014) A global inventory of lakes based on high-resolution satellite imagery. Geophys Res Lett 41:6396-6402. doi:10.1002/2014GL060641

Wan W, Xiao P, Feng X, Li H, Ma R, Duan H, Zhao L (2014) Monitoring lake changes of Qinghai-Tibetan Plateau over the past 30 years using satellite remote sensing data. Chin Sci Bull 59(10):1021-1035

Wang B, Bao Q, Hoskins B, Wu G, Liu Y (2008) Tibetan Plateau warming and precipitation change in East Asia. Geophys Res Lett 35:L14702. doi:10.1029/2008GL034330

Wang G, Liu G, Liu LA (2012) Spatial scale effect on seasonal streamflows in permafrost catchments on the Qinghai-Tibet Plateau. Hydrol Process 26(7):973-984

Wang X, Gong P, Zhao Y et al (2013) Water-level changes in China's large lakes determined from ICESat/ GLAS data. Remote Sens Environ 132:131-144

Wei J, Liu S, Guo W, Yao X, Xu J, Bao W, Jiang Z (2014) Surface-area changes of glaciers in the Tibetan Plateau interior area since the 1970s using recent Landsat images and historical maps. Ann Glaciol 55(66):213-222 
Williamson CE, Saros JE, Vincent WF, Smol JP (2009) Lakes and reservoirs as sentinels, integrators, and regulators of climate change. Limnol Oceanogr 54(6):2273

Wingham DJ, Rapley CG, Griffiths H (1986) New techniques in satellite altimeter tracking systems. In: Proceedings of IGARSS'86 Symposium, Zürich, 8-11 Sept 1986, ESA SP-254 (pp 1339-1344)

Wu Y, Zhu L (2008) The response of lake-glacier variations to climate change inNam Co Catchment, central Tibetan Plateau, during 1970-2000. J Geogr Sci 18:177-189

Wu Y, Zheng H, Zhang B, Chien D, Lei L (2014) Long-term changes of lake level and water budget in the Nam Co Lake basin, Central Tibetan Plateau. J Hydrometeorol 15:1312-1322

Xu HQ (2006) Modification of normalised difference water index (NDWI) to enhance open water features in remotely sensed imagery. Int J Remote Sens 27:3025-3033

Xu ZX, Gong TL, Li JY (2008) Decadal trend of climate in the Tibetan Plateau regional temperature and precipitation. Hydrol Process 22:3056-3065

Yao T, Pu J, Lu A, Wang Y, Yu W (2007) Recent glacial retreat and its impact on hydrological processes on the Tibetan Plateau, China, and surrounding regions. Arct Antarct Alp Res 39(4):642-650

Yao T, Thompson LG, Mosbrugger V, Zhang F et al (2012) Third pole environment (TPE). Environ Dev 3:52-64

Ye Q, Zhu L, Zheng H, Naruse R, Zhang X, Kang S (2007) Glacier and lake variations in the YamzhogYumco basin, southern Tibetan Plateau, from 1980 to 2000 using remote-sensing and GIS technologies. J Glaciol 53(183):673-676

Yi Y, Kouraev AV, Shum CK, Vuglinsky VS, Cretaux J-F, Calmant S (2013) The performance of altimeter waveform retrackers at lake Baikal. Terr. Atmos Sci 24(4I):513-519. doi:10.3319/TAO.2012.10.09.01

Zhang G, Xie H, Kang S, Yi D, Ackley S (2011a) Monitoring lake level changes on the Tibetan Plateau using ICESat altimetry. RSE 115:1733-1742. doi:10.1016/j.rse.2011.03.005

Zhang B, Wu Y, Zhu L, Wang J, Li J, Chen D (2011b) Estimation and trend of water storage at Nam Co Lake, central Tibetan Plateau. J Hydrol 405:161-170

Zhang G, Yao T, Xie H, Kang S, Lei Y (2013) Increased mass over the Tibetan Plateau: from lakes or glaciers? Geophys Res Lett 40(10):2125-2130

Zhang G, Yao T, Xie H, Wang W, Yang W (2015) An inventory of glacial lakes in the Third Pole region and their changes in response to global warming. Glob Planet Change 131:148-157

Zwally HJR, Schutz C, Bentley J, Bufton T, Herring J, Minster J, Spinhirne RT (2003) GLAS/ICESat L1B global elevation data, version 33: GLA 06. Boulder, Colorado, USA 